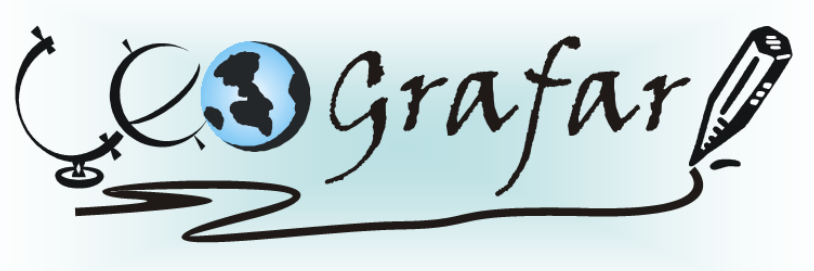

Revista Eletrônica do Programa de Pós-Graduação em Geografia - UFPR

\title{
AVALIACCÃO DO MÉTODO DE DIAGNÓSTICO FÍSICO CONSERVACIONISTA (DFC) EM BACIAS HIDROGRÁFICAS ATRAVÉS DA ESTATÍSTICA MULTIVARIADA
}

\section{EVALUATION OF THE METHOD OF PHYSICAL DIAGNOSIS CONSERVATIONIST (PDC) IN WATERSHED THROUGH STATISTICAL MULTIVARIATE}

(Recebido em 02.06.2014; Aceito em: 20.02.2015)

Marcia Regina Gomes de Jesus Soares

Doutoranda em Geografia

Universidade Federal do Paraná

Curitiba, PR, Brasil

e-mail:marcia.rgsoares@gmail.com

Chisato Oka-Fiori

Profa. Dra ${ }^{a}$, Depto. de Geografia

Universidade Federal do Paraná

Curitiba, PR, Brasil

e-mail:piofiori@terra.com.br

Eloy Kaviski

Prof. Dr., Depto. de Recursos Hídricos Universidade Federal do Paraná

Curitiba, PR, Brasil e-mail: eloy.dhs@ufpr.br

Claudinei Taborda da Silveira Professor Dr., Depto. de Geografia Universidade Federal do Paraná

Curitiba, PR, Brasil e-mail: claudineits@ufpr.br

\section{RESUMO}

No presente trabalho são apresentados os resultados de um estudo cujo objetivo geral é validar, com dados hidrológicos de vazão, o método de diagnóstico físico conservacionista (DFC) em bacias hidrográficas, na escala regional, através da análise estatística multivariada visando contemplar variáveis para a análise e gestão 
de elementos físicos da paisagem e seus processos. O método do DFC é um modelo que indica parâmetros potenciais que serão expressos em forma numérica estabelecendo o potencial de degradação e possibilitando uma análise qualitativa quanto à preservação desses recursos. O método foi aplicado em 14 sub-bacias hidrográficas ao longo do rio Ivaí - PR, cujo exutório coincidisse com as estações de registro de vazão, visando compor os pontos amostrais para a análise estatística de correlação canônica. O resultado da correlação canônica, representada pelo $R$ canônico foi igual a 0.978 com $R^{2}$ canônico igual a 0.957 , qui-quadrado $(x 2)$ de 26.681 e GL (graus de liberdade) igual a 9, o que é muito significativo e expressa alta correlação entre o método e as vazões. Estes resultados confirmam a hipótese de que o DFC pode ser validado pela vazão, pois de acordo com os resultados, eles não são independentes e estão altamente relacionados.

Palavras-chave: Correlação canônica; vazões; hidrologia; diagnóstico físico conservacionista.

\begin{abstract}
The results of a study whose overall objective is to validate with hydrological flow data, the method of physical conservation diagnosis (PCD) in watersheds on a regional scale, through statistical analysis are presented in this work include multivariate order variables for the analysis and management of physical elements of the landscape and its processes. The method of PCD is a model that indicates potential parameters to be expressed in numerical form indicating potential degradation and enabling a qualitative analysis for the preservation of these resources. The method was applied to 14 sub-basins along the river Ivaí - PR, whose outfall coincide with sampling stations flow, aiming at building the sampling points for the statistical analysis of canonical correlation. The result of canonical correlation, represented by canonical $R$ was equal to 0.978 with canonical $R^{2}$ equal to 0.957 , chisquare $\left(x^{2}\right)$ of 26.681 and $G L$ (degrees of freedom) equal to 9 , which is very significant and expressed high correlation between the method and flow rates. These results confirm the hypothesis that the PCD can be validated by the flow, because according to the results, they are not independent and are highly related.
\end{abstract}

Keywords: Canonical correlation; flows; hydrology; physical conservation diagnosis.

\title{
INTRODUÇÃO
}

A formulação de conhecimentos aprofundados visando o fornecimento de subsídios técnico-científicos auxiliares nas questões de planejamento territorial, principalmente aqueles voltados ao uso do solo, para o estabelecimento de relações mais equilibradas entre sociedade e meio natural, tem direcionado estudos de cientistas e pesquisadores (NEVES, 2012; MENDONÇA; MARQUES, 2011; 
FERRETTI, 2003; LEPSCH, 2002; ALVARENGA; PAULA, 2000; RAMALHO FILHO; BEEK, 1994; ROSS, 1994).

A realização do diagnóstico do meio físico e socioeconômico, com as condições de uso em escala multitemporal do solo aliados às técnicas disponíveis como estatística e pesquisa operacional são fundamentais. Tendo em vista a quantidade de metodologias existentes na literatura que objetiva a análise do meio físico, nota-se a carência de inserção de variáveis significativas, como as hidrológicas. Além disso, quando se trabalha com métodos que atribuem pesos numéricos para a geração de matrizes resultantes da inter-relação de variáveis importantes, como declividade, tipos de solo, uso do solo, por exemplo, fica a dúvida da veracidade destes resultados. Neste artigo foi verificado com interesse de comprovação o argumento implícito no método DFC de que a agricultura e pastagem oferecem $40 \%$ e $60 \%$ de proteção em relação à vegetação natural respectivamente. Se os corpos d'água oferecem mesmo $10 \%$ de proteção em relação à cobertura vegetal, como o método propõe (BELTRAME, 1994; CARVALHO, 2004). Os critérios do método e a que processos de proteção servem necessitam de esclarecimentos e os argumentos para o emprego desses valores nem sempre são apresentados.

Partindo destes pressupostos, a motivação para o desenvolvimento desta pesquisa baseia-se na intenção em contemplar a variável de vazão em seus diversos aspectos (vazões média, máximas e mínimas de 07, 15, 30, 60 e 90 dias) para a análise e gestão de elementos físicos da paisagem e seus processos, o que é extremamente necessário para se chegar a resultados significativos. Também da preocupação de verificar se métodos a exemplo do DFC que se fundamentam na atribuição de pesos numéricos para se chegar a generalizações no levantamento de informações sobre áreas estudadas são coerentes com a realidade refletida nos processos hidrológicos por meio de correlações estatísticas.

Sendo assim, os objetivos da pesquisa podem ser resumidos em validar, com dados hidrológicos de vazão, o método de diagnóstico físico conservacionista (DFC) em bacias hidrográficas, na escala regional, através da análise estatística multivariada.

A área de estudo da presente pesquisa, designada bacia hidrográfica do Ivaí (Figura 1), foi selecionada por apresentar dados de vazão e chuva adequados aos 
objetivos propostos, além de mapas regionais na escala 1:250.000, afim de verificação se o DFC, método analisado, mostra compatibilidade com esta escala, com as imagens no formato raster e com os dados hidrológicos.

A bacia hidrográfica do Ivaí, inteiramente inserida no território paranaense, nas regiões que compreende o segundo e o terceiro planalto, apresenta área total de $35.845,0 \mathrm{~km}^{2}$. Entretanto, houve diferença da área de estudo em relação à área total da bacia (Figura 1), tendo em vista as estações de monitoramento e registro dos dados de vazão, pois a última estação, bem no exutório do rio Ivaí, não apresentou dados que atendessem a escala temporal mínima de 27 anos como as demais estações, e por isso teve de ser descartada, reduzindo a área de estudo para $34.419,0 \mathrm{~km}^{2}$.

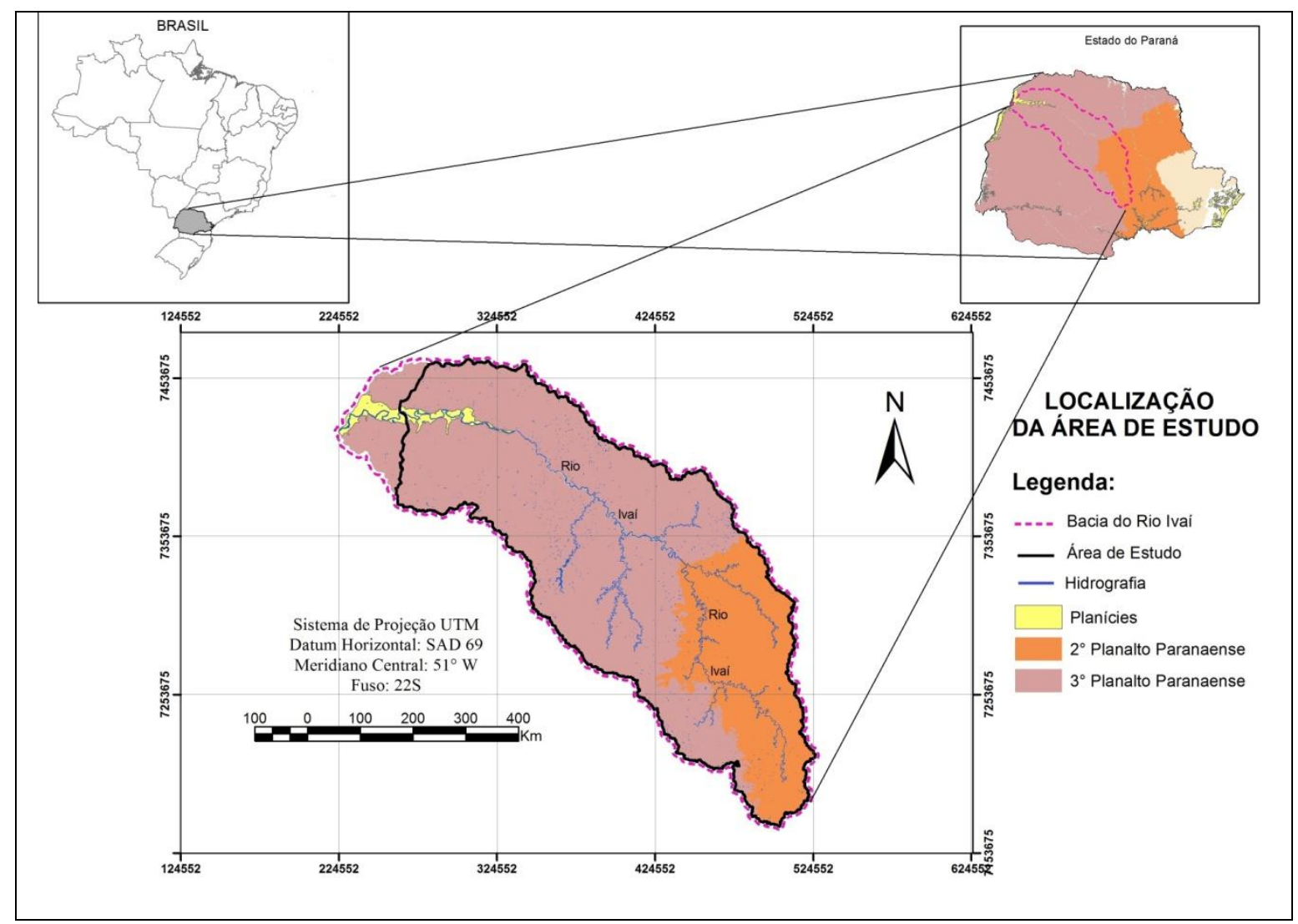

Figura 1 - Localização da área de estudo: Bacia do rio Ivaí PR.

O rio Ivaí surge da confluência dos rios dos Patos e São João, na Porção Sul do Estado do Paraná, precisamente na região denominada Serra da Boa Esperança, na divisa dos municípios de Prudentópolis e Ivaí (BALDO, 2006). 
Os materiais geológicos são correspondentes ao grupo Passa Dois, compreendendo as formações Irati, Serra Alta, Terezina e Rio do Rasto; Grupo São Bento, que abrange as formações Piramboia e Botucatu; Formação Serra Geral, que recobriu uma grande parte do imenso deserto de Botucatu; o arenito da Formação Caiuá do grupo Bauru; e, em alguns locais, parcialmente recobertas por sedimentos inconsolidados. (BALDO, 2006).

Segundo Maack (1981), o sistema orográfico da bacia do rio Ivaí evidencia claramente a correlação das formas existentes com a constituição geológica. As altitudes na bacia variam de menos 300 a mais de 1.300 metros desde a foz até a nascente. O rio Ivaí nasce no Segundo Planalto e corta todo o Terceiro Planalto em sentido noroeste.

Essa bacia por apresentar grande extensão territorial possui também uma variedade muito grande de solos. Dentre os mais encontrados, destacam-se: Cambissolos, Latossolos, Argissolos, Nitossolos e os Neossolos, segundo a classificação da Empresa Brasileira de Pesquisa Agropecuária EMBRAPA (2008), atualizadas a partir dos dados obtidos junto a EMBRAPA (1984).

Segundo o Instituto Agronômico do Paraná (IAPAR, 1994) o clima da área de estudo está enquadrado em dois tipos principais; o primeiro é tropical e abrange o curso inferior e o médio da bacia, e o segundo, subtropical e compreende o curso superior da bacia. Na porção do baixo Ivaí, os maiores valores médios de temperatura acima de $22{ }^{\circ} \mathrm{C}$ ocorrem em outubro, janeiro e dezembro, enquanto os menores valores, em torno dos $9 \stackrel{\circ}{\circ} \mathrm{C}$, acontecem nos meses de agosto, julho e abril (CARAMORI, 1989), associado ao tipo de cobertura pedológica predominante, favorecem o desenvolvimento de vegetação tipo floresta (Floresta Estacional Semidecidual e Floresta Ombrófila Mista).

\section{MATERIAL E MÉTODOS}

Para realizar o levantamento das principais características do meio físico da área de estudo foram utilizados os seguintes materiais: Levantamento SRTM (Shuttle Radar Topography Mission), versão 1, em formato raster com resolução espacial de 90 × 90 metros, ano de 2003; Base hidrográfica do Estado do Paraná, escala 1:50.000 (ÁGUASPARANÁ, 2011); Levantamento geológico do Estado do 
Paraná, escala 1:250.000 (MINEROPAR, 2006); Base geomorfológica do Estado do Paraná, escala 1:250.000 (OKA FIORI et al., 2006); Levantamento de Reconhecimento dos Solos do Estado do Paraná, escala 1:250.000 (EMBRAPA, 2008); Imagens do satélite LANDSAT TM 5, ano de 1986, 2000 e 2011 fornecidas pelo INPE (2013); Software ARCGIS versão 10.1; Software ENVI versão 4.5; Software estatístico BioEstat 5.3.

Para aplicar e proceder com a validação do método da análise fisico-funcional em bacias hidrográficas alguns procedimentos prévios foram realizados, e estão descritos a seguir.

Para a execução das análises geo-espaciais dos dados coletados nas bacias hidrográficas e os dados compilados de outras fontes foi criado um banco de dados georreferenciados em ambiente SIG, e utilizadas técnicas de Sensoriamento Remoto. Os modelos digitais utilizados (vetorial, raster e de elevação - MDE) possibilitaram modelar a superfície do terreno preservando as feições geomórficas da superfície, pois atendem a diversas escalas de análise, principalmente escalas regionais, como nesta pesquisa, tendo por base sua resolução espacial (FORNELOS; SILVA NEVES, 2006).

A Carta de Solos com as classes pedológicas da área de estudo já em meio digital foi fornecida pela EMBRAPA (2008) na escala 1:250.000. Para a obtenção dos dados hidrológicos de vazão e pluviosidade, foram utilizadas as séries históricas entre 1985 e 2012, período que há dados em comum entre as 14 estações de coleta; o tratamento estatístico dos dados diários em dados anuais foi realizado através da ferramenta EXCEL, como os cálculos de média, desvio padrão, limites superiores e inferiores, intervalos de confiabilidade, correlações e gráficos.

A curva de permanência constitui importante fonte de apontamento do potencial de regularização hidrológica, e ela foi construída por dispor as vazões diárias observadas no período considerado em ordem decrescente. Com a amplitude da variação das vazões, foram definidos os intervalos de classe e colocados os intervalos em ordem decrescente e verificados o número de eventos ocorridos em cada intervalo à frequência absoluta. Foi calculada a frequência relativa (frequência absoluta / número de dados) para cada intervalo e acumuladas seguindo a ordem anterior. Foram plotados gráficos com o limite inferior de cada intervalo (ordenada) e a correspondente frequência relativa acumulada (abscissa). 
Foi calculado também os desvios padrões em relação à média e o coeficiente de variação (relação entre o desvio padrão e a média).

O mesmo procedimento foi aplicado para a elaboração das vazões máxima anual e mínima de 7 dias, 15 dias, 30 dias, 60 dias e 90 dias.

\subsection{Diagnóstico Físico Conservacionista (DFC)}

Para a aplicação do método (DFC) cada parâmetro é definido por um índice de acordo com classificações previamente estabelecidas sendo que, parâmetros e índices sugerem uma análise qualitativa da bacia hidrográfica que está sendo pesquisada (Tabela 1).

Então, a somatória dos índices mínimos de cada parâmetro, estabelece o padrão de melhores condições da bacia hidrográfica. A somatória dos índices máximos de cada parâmetro estabelece o padrão de piores condições da bacia hidrográfica (Equação 1). Portanto, quanto maiores os valores dos subíndices e, consequentemente, dos valores finais, maior o potencial de suscetibilidade de degradação dos recursos da bacia hidrográfica (Tabela 2).

Tabela 1 - Equações utilizadas para o cálculo dos parâmetros fisiográficos do DFC - Bacia do rio Ivaí.

\begin{tabular}{|c|c|c|}
\hline Parâmetro & Equação & Variáveis \\
\hline $\begin{array}{l}\text { CA - proteção da } \\
\text { cobertura vegetal atual } \\
\text { ao solo (adimensional) }\end{array}$ & $I_{c s}=\frac{\sum A u \cdot p e s o}{A}$ & $\begin{array}{l}\text { Ícs - índice de cobertura do solo por sub- } \\
\text { bacia; } \mathrm{Au} \text { - área de cada tipo de cobertura } \\
\text { em } \mathrm{km}^{2} ; \text { peso - peso de cada tipo de } \\
\text { cobertura; } A \text {-área da bacia em } \mathrm{km}^{2}\end{array}$ \\
\hline $\begin{array}{l}\mathrm{CO}-\text { cobertura } \\
\text { vegetal original }\end{array}$ & $C O$ & $\begin{array}{l}\text { Grau de semelhança da cobertura original } \\
\text { com a cobertura atual }\end{array}$ \\
\hline $\begin{array}{l}D M-\text { declividade } \\
\text { média do terreno }\end{array}$ & $D M=\frac{(L C N . E)}{A}$ & $\begin{array}{l}D M=\text { declividade média; } \angle C N=\text { longitude } \\
\text { das curvas de nível (por sub-bacia); } A=\text { área } \\
\text { por sub-bacia. }\end{array}$ \\
\hline $\begin{array}{l}\text { E- erosividade da } \\
\text { chuva }\end{array}$ & $E=6.886\left(\frac{r^{2}}{P}\right)^{0.85}$ & $\begin{array}{l}\text { E- média mensal do índice de erosão em } \\
(\mathrm{t} / \mathrm{ha}) .(\mathrm{mm} / \mathrm{h}) ; r \text { - precipitação média mensal } \\
\mathrm{em} \mathrm{mm} ; \mathrm{P} \text { - precipitação média anual em } \\
\mathrm{mm} \text {. }\end{array}$ \\
\hline $\begin{array}{l}P E-p o t e n c i a l \text { erosivo } \\
\text { dos solos }\end{array}$ & $\frac{A p e \cdot f}{A}$ & $\begin{array}{l}\text { Ipe - indice do potencial erosivo do solo por } \\
\text { sub-bacia; Ape - o total das áreas das } \\
\text { classes de potencial erosivo presente em } \\
\text { cada sub-bacia em } \mathrm{km}^{2} \text {; Fator } \mathrm{k} \text { - valores } \\
\text { superiores dos índices de potencial erosivo; } \\
\text { A - total das áreas das classes de potencial } \\
\text { erosivo presente em cada sub-bacia em } \mathrm{km}^{2} \text {. }\end{array}$ \\
\hline $\begin{array}{l}D D-\text { densidade de } \\
\text { drenagem }\left(\mathrm{km} \mathrm{km}^{-2}\right)\end{array}$ & $D d=\frac{L t}{A}$ & $\begin{array}{l}L t-\text { comprimento total dos canais }(\mathrm{km}) ; A- \\
\text { área da bacia }\left(\mathrm{km}^{2}\right) \text {. }\end{array}$ \\
\hline$B H-$ balanço hídrico & & $\begin{array}{l}E=\text { evapotranspiração }(m m \times a n o-1) ; P= \\
\text { precipitação }(m m \times a n o-1) ; Q=\text { escoamento } \\
(m m \times a n o-1)\end{array}$ \\
\hline
\end{tabular}


Com a obtenção dos valores dos parâmetros esses são inseridos na função descritiva (equação 1):

$$
E(f): C A_{a}+C O_{b}+D M_{c}+E_{d}+P E_{e}+D D_{f}+B H_{g}
$$

Onde:

$\mathrm{CA}_{\mathrm{a}}$ : proteção da cobertura vegetal atual ao solo; "a" é o índice específico do parâmetro, que varia entre 1 (proteção máxima) e 4 (nenhuma proteção).

$\mathrm{CO}_{\mathrm{b}}$ : grau de semelhança entre a cobertura vegetal original e a atual; "a" é o índice específico do parâmetro, que varia de 1 (altamente semelhante) a 5 (nenhuma semelhança).

$\mathrm{DM}_{\mathrm{c}}$ : declividade média; "c" é o índice específico deste parâmetro, que varia entre 1 (relevo plano) e 4 (montanhoso à escarpado).

$E_{d}$ : erosividade da chuva; "d" é o índice específico do setor, que varia entre 1 (erosão débil) e 5 (erosão excessiva).

$\mathrm{PE}_{\mathrm{e}}$ : potencial erosivo dos solos; "e" é o índice específico do parâmetro, que varia de 1 (baixo) a 5 (muito alto).

$\mathrm{DD}_{\mathrm{f}}$ : densidade de drenagem; "f" é o índice específico do parâmetro, que varia de 1 (baixa) a 4 (muito alta).

$\mathrm{BH}_{\mathrm{g}}$ : balanço hídrico; "g" é o índice específico do parâmetro, que varia de 1 (muito alto) e 4 (baixo).

Para cada sub-bacia aplicou-se a fórmula descritiva (equação 1).

Tabela 2 - Síntese dos Setores - Bacia do rio Ivaí.

\begin{tabular}{ccc}
\hline PARÂMETRO & Mínimo & Máximo \\
\hline Cobertura Vegetal Atual & $\mathrm{CA}_{1}$ & $\mathrm{CA}_{4}$ \\
Cobertura Vegetal Original & $\mathrm{CO}_{1}$ & $\mathrm{CO}_{5}$ \\
Declividade Média & $\mathrm{DM}_{1}$ & $\mathrm{DM}_{4}$ \\
Erosividade da Chuva & $\mathrm{E}_{1}$ & $\mathrm{E}_{5}$ \\
Potencial Erosivo dos Solos & $\mathrm{PE}_{1}$ & $\mathrm{PE}_{5}$ \\
Densidade de Drenagem & $\mathrm{DD}_{1}$ & $\mathrm{DD}_{4}$ \\
Balanço Hídrico & $\mathrm{BH}_{1}$ & $\mathrm{BH}_{4}$ \\
SOMATÓRIA DOS ÍNDICES & 07 & 31 \\
\hline
\end{tabular}

Com os valores mínimos e máximos, obteve-se o ângulo de inclinação da reta (equação da reta). Plotou-se no eixo " $x$ " os valores obtidos nas fórmulas descritivas por sub-bacia e, foram traçadas as perpendiculares até a reta, obtendo 
nas ordenadas, as unidades de risco de degradação física da bacia, com a equação 2, da reta:

$$
y=a x+b
$$

Assim, os números finais da função descritiva por sub-bacia foram alcançados em percentuais, com o emprego da equação da reta. Dessa forma com as classificações aplicadas, o valor mínimo possível de ser obtido na fórmula descritiva é 7 (somatório de todos os índices iguais a 1) o que expressa o melhor estado físico-conservacionista de que poderia apresentar a sub-bacia; o valor mais alto possível de se alcançar na fórmula descritiva para as sub-bacias do rio Ivaí é 31 (somatória de todos os índices com valores máximos) o que expressa o pior estado físico-conservacionista que a sub-bacia poderia apresentar. Com estes valores mínimos de 7 e máximo de 31, tem-se o ângulo de inclinação da reta:

$$
\begin{aligned}
& \text { Se } y=0 \\
& x=7 \\
& \text { Se } y=100 \\
& x=31 \\
& 7 \mathrm{a}+\mathrm{b}=0 \\
& 31 a+b-100=0 \\
& 7 a+b=0 \quad(-1) \\
& 31 a+b-100=0 \\
& \begin{array}{rl}
a=4,17 & 24 a \quad-100=0 \\
y=4,17 x-29,17 & b=-29,17
\end{array}
\end{aligned}
$$

\section{Análise de Correlação Canônica (ACC)}

O objetivo da correlação canônica é relacionar simultaneamente múltiplas variáveis dependentes e independentes. A correlação canônica mede a força da associação entre os dois conjuntos de variáveis. A força do relacionamento entre os pares de variáveis é refletida principalmente pelos coeficientes canônicos de uma primeira função ( $R$ canônico). Quando elevados ao quadrado ( $R^{2}$ canônico), tais coeficientes representam a quantidade de variância em um composto linear da função canônica atribuída a outro composto da mesma função. Pode-se assim, relacionar determinados dados hidrológicos com variáveis que caracterizam o estado físico da bacia hidrográfica.

$\mathrm{Na}$ literatura existente, foram encontrados poucos trabalhos referentes a processos em bacias hidrográficas que utilizam a análise de correlação canônica. 
Entretanto, pode-se destacar o uso desta técnica em pesquisas hidrológicas encontradas em Torranin (1972) e Ebisemiju (1988). Os trabalhos de alguns autores que utilizaram esta técnica na área da química, administração e engenharia, podem ser encontrados em Trugilho et al. (2003), Costa (2008) e Bogo et al. (2010), respectivamente.

Nesta pesquisa, para se atender aos objetivos propostos - conhecer e avaliar quais determinantes físicas melhor explicam o comportamento hidrológico nas subbacias a fim de validação do método DFC, foram confrontados os dados de vazões (X = Q(TP); DESVPAD; CV; $Q$ (máx); $Q($ mín7); $Q$ (mín15); $Q$ (mín30); $Q($ mín60); Q(mín90)) com as variáveis fisiográficas (Y = DFC médio (anos de 1986, 2000 e 2011), de 14 sub-bacias hidrográficas.

\section{RESULTADOS}

O resultado da subdivisão da bacia do rio Ivaí em 14 (quatorze) sub-bacias de acordo com as informações fluviométricas que equivalem a 14 pontos amostrais, como dados estatísticos, podem ser visualizados na Tabela 3 e na Figura 2.

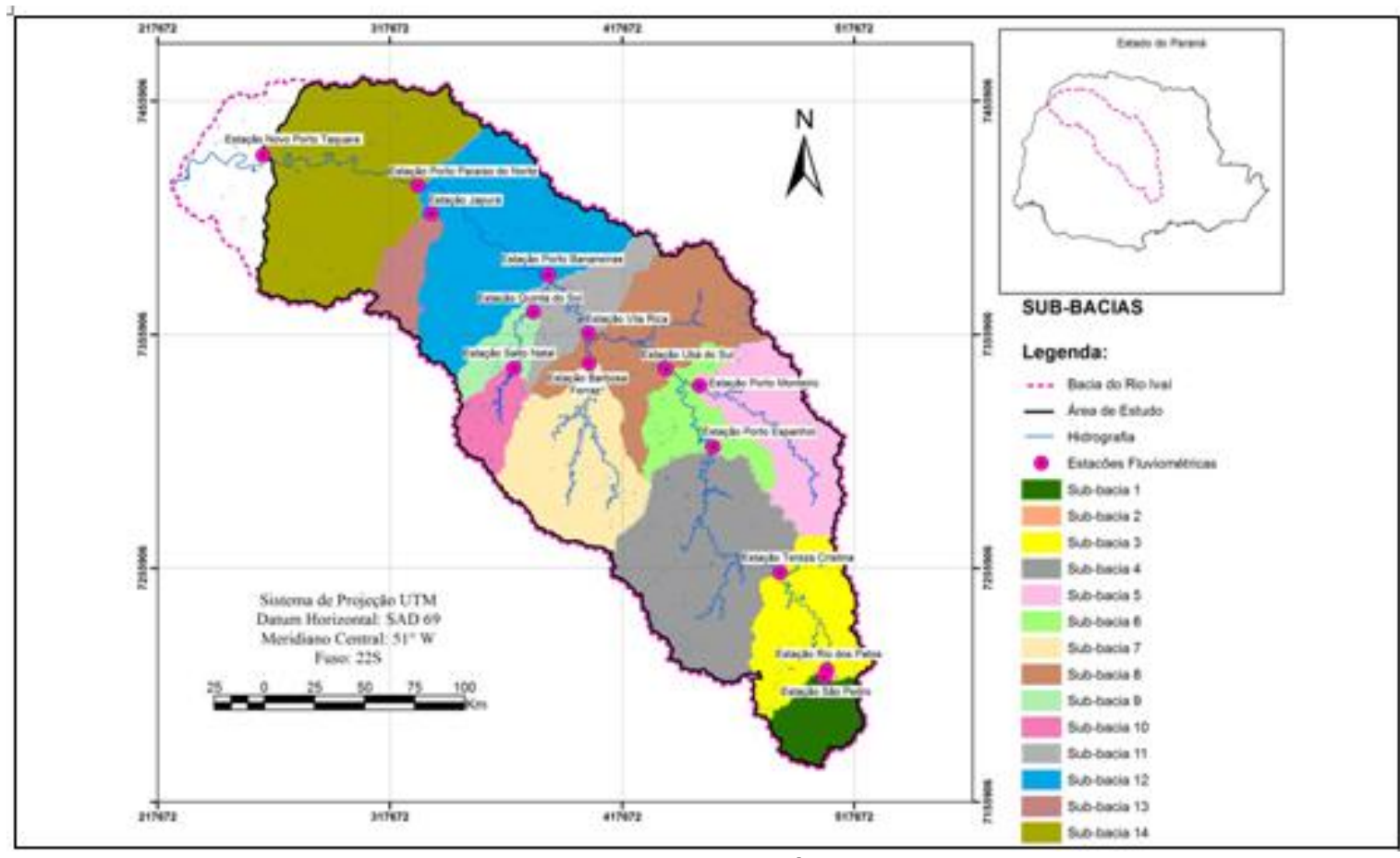

Figura 2 - Divisão da bacia do rio Ivaí - PR em 14 sub-bacias. 
A sub-bacia 14 possui exutório que coincide com o último posto de monitoramento de vazão da área total de estudo. As sub-bacias que não recebem contribuição de áreas e aportes hidrográficos de sub-bacias à montante, além da 1 são a 5 , a 7 , a 10 e a 13.

Tabela 3 - Informações fluviométricas da bacia do rio Ivaí.

\begin{tabular}{|c|c|c|c|c|c|}
\hline Sub-bacia & Código & Estação & Rio & Município & Área $\left(\mathrm{km}^{2}\right)$ \\
\hline 1 & 64619950 & SÄO PEDRO & Rio dos Patos & Prudentópolis & 1054,1 \\
\hline 2 & 64620000 & RIO DOS PATOS & Rio dos Patos & Prudentópolis & 1089,6 \\
\hline 3 & 64625000 & TEREZA CRISTINA & Rio lvaí & Cândido de Abreu & 3566,5 \\
\hline 4 & 64645000 & PORTO ESPANHOL & Rio lvaí & Rio Branco do Ivaí & 8545,2 \\
\hline 5 & 64652000 & PORTO MONTEIRO & Rio Alonzo & Grandes Rios & 2611,9 \\
\hline 6 & 64655000 & UBA DO SUL & Rio lvaí & Lidianópolis & 12703,8 \\
\hline 7 & 64659000 & BARBOSA FERRAZ & Rio Corumbataí & Barbosa Ferraz & 3277,1 \\
\hline 8 & 64660500 & VILA RICA & Rio lvaí & Fênix & 19436,1 \\
\hline 9 & 64673000 & QUINTA DO SOL & Rio Mourão & Quinta do Sol & 1553,3 \\
\hline 10 & 64671000 & SALTO NATAL & Rio Mourão & Campo Mourão & 854,2 \\
\hline 11 & 64675002 & PORTO BANANEIRAS & Rio lvaí & Engenheiro Beltrão & 22498,5 \\
\hline 12 & 64685000 & PORTO PARAISO DO NORTE & Rio lvaí & Rondon & 28403,1 \\
\hline 13 & 64682000 & JAPURA & Rio dos Indios & Japurá & 802,5 \\
\hline 14 & 64693000 & NOVO PORTO TAQUARA & Rio lvaí & Douradina & 34419,3 \\
\hline
\end{tabular}

\section{Proteção da Cobertura Atual ao Solo - Parâmetro CA}

As categorias de uso da terra foram adaptadas do Manual do Uso da Terra do IBGE (2013): Corpos d'água, Vegetação, Pastagem, Agricultura e Áreas Urbanas e podem ser visualizadas na Tabela 4 e Figura 3. Verificou-se que as ocupações mais expressivas na bacia do rio Ivaí são agricultura e pastagem que se concentram em toda a área, principalmente na parte central em direção à foz do rio principal, e vegetação, que se concentra na parte superior, próxima a cabeceira.

Tabela 4. Principais classes de uso e ocupação da bacia do rio Ivaí, nos anos de 1986, 2000 e 2011 em relação à área total da bacia e variações.

\begin{tabular}{l|cccccc}
\hline Usos & \multicolumn{3}{|c}{ Ocupação da bacia (\%) } & \multicolumn{3}{c}{ Variações (\%) entre: } \\
& 1986 & 2000 & 2011 & 86 e 00 & 00 e 11 & 86 e 11 \\
\hline Corpos d'água & 0.5 & 0.5 & 0.5 & 0.0 & 0.0 & 0.0 \\
Vegetação & 17.5 & 12.6 & 16.3 & -4.9 & 3.7 & -1.2 \\
Pastagem & 20.4 & 19.8 & 12.4 & -0.6 & -7.3 & -7.9 \\
Agricultura & 61.1 & 66.3 & 69.7 & 5.2 & 3.4 & 8.6 \\
Áreas Urbanas & 0.5 & 0.9 & 1.1 & 0.4 & 0.2 & 0.5 \\
Total & 100.0 & 100.0 & 100.0 & 0.0 & 0.0 & 0.0 \\
\hline
\end{tabular}



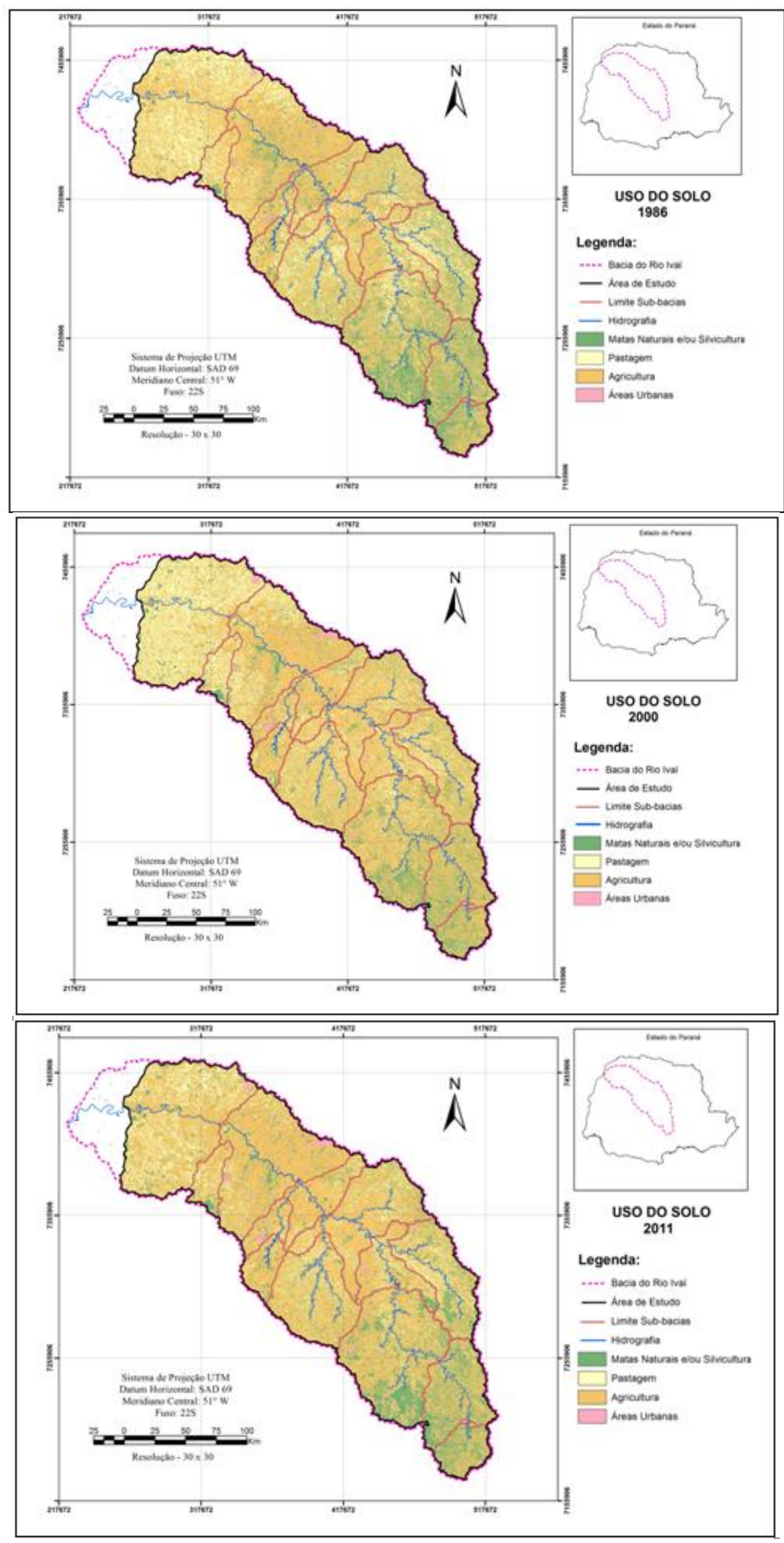

Figura 3 - Carta das classes de uso do solo da bacia do rio Ivaí: 1986, 2000 e 2011. 
Para a classe Corpos d'água não houve alterações e a classe de uso Vegetação, referente ao ano de 1986, representava $17,5 \%$ da área de estudo, com queda de 4,9\% em relação ao ano de 2000 e com aumento de 3,7 no percentual em 2011, e queda geral no período de 1,2\%. Esta classe envolve tanto florestas naturais, reflorestamento bem como silvicultura, tendo em vista que esta última ocupação não demanda uso muito intensivo do solo, em comparação com as atividades agrícolas anuais. De acordo com Campos (2013), que analisou a evolução multitemporal do solo para verificar a evolução da vegetação em dois trechos da bacia do rio Ivaí, o reflorestamento aumentou na área estudada em 2010 em comparação a 1970.

Segundo o autor, este aumento pode ter sido motivado pelo processo de conscientização dos proprietários rurais quanto à importância dessas áreas para a melhoria da qualidade ambiental local, por ações de incentivos dos programas governamentais para a restauração de matas ciliares, por exigências legais impostas pelos agentes fiscais, ou todas essas motivações conjuntamente. Isso pode explicar a queda até 2000 na vegetação e depois o aumento em relação a 2011, tendo em vista que o Decreto Estadual n 387 data do dia 02 de março de 1999, que Institui o Sistema de Manutenção, Recuperação e Proteção da Reserva Florestal Legal e Áreas de Preservação Permanente - SISLEG, no Estado do Paraná (PARANÁ, 1999).

Esse decreto auxilia no aumento das áreas florestais, tendo em vista que instrumentos legais, quando associados com o planejamento da locação das áreas de reserva legal e restauração das Áreas de Preservação Permanente nas propriedades privadas, podem contribuir para a proteção de áreas de fragilidade ambiental e unidades de conservação. Isso possibilita contribuição efetiva para a melhoria da qualidade ambiental, pois, todas as ações a serem desenvolvidas no processo de conservação da biodiversidade devem buscar o desenvolvimento econômico da coletividade, tendo como horizonte e base a sustentabilidade ambiental e social (CAMPOS, 2013).

A classe Pastagem em 1986 representava 20,4\% da área total, diminuiu para 19,8\% em 2000; em 2011 a mesma ocupação diminuiu ainda mais o percentual de uso, apresentando na variação queda geral de 7,9\%. Ao se comparar a agricultura da área praticada no ano de 2000 em relação a 1986 (Tabela 3), pode-se notar que 
houve aumento da classe de uso em 5.2\% com aumento de $3.4 \%$ do uso para esta classe em 2011, resultando em aumento geral de 8.6\%. Para a classe de uso: Áreas Urbanas, a ocupação em 1986 consistia em $0.5 \%$ do total geral da área da bacia do rio Ivaí, com aumento para $0.9 \%$ em 2000. No ano de 2011 esta classe passou a representar $1.1 \%$, apresentando aumento de $0.2 \%$ em relação a 2000 e aumento de $0.5 \%$ no total geral do período (1986 a 2011). As características favoráveis à agricultura, devido aos solos de alta fertilidade e declividades não tão acentuadas existentes na bacia do Rio Ivaí, propiciaram a implantação e o desenvolvimento de uma agricultura altamente tecnificada. Atualmente a região é uma das principais fornecedoras de matérias-primas para as agroindústrias, e entre os produtos oferecidos destacam-se a cana, a soja e o milho (CAMPOS, 2013).

Segundo o mesmo autor esses fatos foram determinantes no sentido de que a agroindústria regional emergiu como uma das principais potências do país, tendo empresas de grande porte, como a COCAMAR (Cooperativa Agroindustrial de Maringá) e a COAMO (Cooperativa Mista Agropecuária Mourãoense Ltda.). Com isso é natural que parte de regiões antes ocupadas com pastagem fossem substituídas pela agricultura, o que explica a sua diminuição em decorrência do aumento da classe agrícola e do reflorestamento na beira dos rios.

Estes dados são ainda confirmados pelo IBGE (2011) que evidencia o aumento da área para o uso da terra do estado do Paraná relacionada à agricultura: 60.625,59 $\mathrm{km}^{2}$ para o ano de $1985,73.611,00 \mathrm{~km}^{2}$ para o ano de 2000 e $86.746,85 \mathrm{~km}^{2}$ para o ano de 2011.

Em relação ao uso com pastagem, em 1985 ocupava uma área de 59.996,04 $\mathrm{km}^{2}$ e em 2009 diminuiu sua superfície para 47.025,46 km², redução de 12.970,58 $\mathrm{km}^{2}$ para a pecuária, com aumento de $26.121,26 \mathrm{~km}^{2}$ para a agricultura, esta última no período de 1985 a 2011 (CANTO et al., 2010).

O resultado do índice de proteção da cobertura atual aplicado à bacia do rio Ivaí por sub-bacia para os anos de 1986, 2000 e 2011 está exposto na Tabela 5.

Considerando-se que o índice de proteção não está relacionado com a semelhança botânica entre as espécies originais e atuais, mas refere-se às características de densidade da cobertura vegetal (BELTRAME, 1994), foram agrupadas as formações florísticas que apresentaram o mesmo índice de proteção ao solo para um mesmo tipo de uso. 
Tabela 5 - Parâmetro CA por sub-bacia do rio Ivaí referente aos anos de 1986, 2000 e 2011

\begin{tabular}{cccccccc}
\hline ANO & \multicolumn{2}{c}{1986} & \multicolumn{3}{c}{2000} & & 2011 \\
SUB- & Índice & Parâmetro & Índice & Parâmetro & Índice & Parâmetro \\
BACIA & & & & & & \\
\hline 1 & 0.58 & $C A_{2}$ & 0.55 & $C A_{2}$ & 0.57 & $C A_{2}$ \\
2 & 0.58 & $C A_{2}$ & 0.55 & $C A_{2}$ & 0.57 & $C A_{2}$ \\
3 & 0.58 & $C A_{2}$ & 0.53 & $C A_{2}$ & 0.57 & $C A_{2}$ \\
4 & 0.57 & $C A_{2}$ & 0.51 & $C A_{2}$ & 0.54 & $C A_{2}$ \\
5 & 0.54 & $C A_{2}$ & 0.49 & $C A_{3}$ & 0.52 & $C A_{2}$ \\
6 & 0.55 & $C A_{2}$ & 0.50 & $C A_{2}$ & 0.53 & $C A_{2}$ \\
7 & 0.51 & $C A_{2}$ & 0.47 & $C A_{3}$ & 0.47 & $C A_{3}$ \\
8 & 0.51 & $C A_{2}$ & 0.49 & $C A_{3}$ & 0.51 & $C A_{2}$ \\
9 & 0.47 & $C A_{3}$ & 0.45 & $C A_{3}$ & 0.44 & $C A_{3}$ \\
10 & 0.48 & $C A_{3}$ & 0.45 & $C A_{3}$ & 0.45 & $C A_{3}$ \\
11 & 0.52 & $C A_{2}$ & 0.48 & $C A_{3}$ & 0.50 & $C A_{2}$ \\
12 & 0.51 & $C A_{2}$ & 0.48 & $C A_{3}$ & 0.49 & $C A_{3}$ \\
13 & 0.49 & $C A_{3}$ & 0.52 & $C A_{2}$ & 0.49 & $C A_{3}$ \\
14 & 0.51 & $C A_{2}$ & 0.49 & $C A_{3}$ & 0.49 & $C A_{3}$ \\
\hline
\end{tabular}

Legenda: $\mathrm{CA}_{2}=$ Média proteção; $\mathrm{CA}_{3}=$ Baixa proteção .

De acordo com as informações contidas na Tabela 5, das sub-bacias ao longo do rio Ivaí para o ano de 1986, três apresentaram baixa proteção em relação à cobertura atual (sub-bacias 9, 10 e 13). Todas as demais sub-bacias tiveram seus índices dentro da média proteção $\left(\mathrm{CA}_{2}\right)$, variando de 0,51 (sub-bacia 7) a 0,58 (subbacia 3).

Em relação ao ano de 2000, oito sub-bacias ao longo do rio Ivaí apresentaram baixa proteção em relação à cobertura atual, com índices variando de 0,45 (subbacia 9) a 0,49 (sub-bacias 5, 8 e 14). No geral, isto significa piora se comparado ao ano de 1986, com três índices na mesma condição. Os demais índices se situaram na condição de média proteção do solo em relação à cobertura atual, um nível acima.

Do total de sub-bacias, seis apresentaram piora em seus índices, sendo a 5, 7, 8, 11, 12 e 14 a ponto de mudarem da condição de média proteção para compor o nível de baixa proteção. Apenas a sub-bacia 13 apresentou melhora, com elevação no índice a ponto de sair da condição de baixa para média proteção em relação à cobertura atual.

No que se refere ao ano de 2011, houve seis sub-bacias que apresentaram baixa proteção em relação à cobertura atual (sub-bacias 7, 9, 10, 12, 13 e 14), com índices entre 0,44 e 0,49. As demais sub-bacias apresentaram índices variando de 
0,50 (sub-bacia 11) a 0,57 (sub-bacias 1, 2 e 3), com média proteção em relação à cobertura atual.

Comparando com o ano de 2000 houve uma leve melhora no índice, pois duas sub-bacias saíram da condição de baixa para média proteção (sub-bacias 5, 8 e 11). No entanto, a sub-bacia 13 apresentou piora no índice, saindo da condição de média proteção e voltando a condição que dispunha em 1986, de baixa proteção do solo em relação à cobertura atual.

\section{Cobertura Vegetal Original - Parâmetro CO}

Na bacia hidrográfica do rio Ivaí encontra-se como principal vegetação a Floresta com Araucária, classificada pelo IBGE como sendo do tipo Floresta Ombrófila Mista (VELOSO et al., 1991), que originalmente ocupava cerca de $40 \%$ do território do Paraná, 30\% de Santa Catarina e 25\% do Rio Grande Sul, e atualmente não passa de 1\% da floresta original (IBAMA, 2005).

Para apresentação dos resultados de forma clara, tanto quantitativa como qualitativamente, optou-se pela elaboração da matriz de semelhança para a mensuração da área vegetacional e o tipo que a substituiu em cada período multitemporal (referente aos anos de 1986, 2000 e 2011). Assim, na Tabela 6 estão apresentados os resultados do grau de semelhança entre a cobertura vegetal original para as sub-bacias 1 a 14 referentes à área da pesquisa.

De acordo com os resultados, de todas as sub-bacias nos três períodos analisados, o grau de semelhança em sua maioria apresentou-se de baixa a nenhuma semelhança, tendo em vista que a vegetação original encontra-se bastante descaracterizada, principalmente pelas atividades agropecuárias (CAMPOS, 2013).

Devido a sua importância ambiental o rio Ivaí foi considerado como uma das áreas estratégicas para a conservação e recuperação da biodiversidade do Paraná reconhecida pela Resolução Conjunta SEMA/IAP n005/2009 de 29 de setembro de 2009 (PARANÁ, 2009).

De acordo com IPARDES (2007), das tipologias representativas da cobertura vegetal original da bacia do rio Ivaí que representavam 99,45\% da área total da bacia $(70,26 \%$ com Floresta Estacional Semidecidual, 29,19\% com a Floresta Ombrófila Mista), passaram a representar 6,41\% de sua área total em 1980 
e entre 2001 e 2002 teve um pequeno acréscimo, subindo para 7,62\%. Esta modesta melhora não foi refletida intensamente em 2000 quando comparada a 1986 no sentido de aumento dos índices, pois se verifica que 5 sub-bacias apresentaram piora no período (sub-bacias 1, 2, 3, 5 e 11). Embora nenhuma sub-bacia tenha melhorado os índices, o que se pode notar de positivo é o fato de que todas as demais sub-bacias mantiveram seus índices no período (Tabela 6).

Tabela 6 - Parâmetro CO por sub-bacia para o ano de 1986, 2000 e 2011.

\begin{tabular}{ccccccc}
\hline $\begin{array}{c}\text { ANO } \\
\text { SUB- } \\
\text { BACIA }\end{array}$ & \multicolumn{2}{c}{1986} & \multicolumn{2}{c}{2000} & \multicolumn{2}{c}{2011} \\
\hline 1 & 43.2 & $\mathrm{CO}_{3}$ & 36.1 & $\mathrm{CO}_{4}$ & 43.1 & $\mathrm{CO}_{3}$ \\
2 & 42.9 & $\mathrm{CO}_{3}$ & 35.7 & $\mathrm{CO}_{4}$ & 42.5 & $\mathrm{CO}_{3}$ \\
3 & 43.4 & $\mathrm{CO}_{3}$ & 32.1 & $\mathrm{CO}_{4}$ & 40.6 & $\mathrm{CO}_{4}$ \\
4 & 37.9 & $\mathrm{CO}_{4}$ & 25.9 & $\mathrm{CO}_{4}$ & 34.3 & $\mathrm{CO}_{4}$ \\
5 & 22.4 & $\mathrm{CO}_{4}$ & 13.9 & $\mathrm{CO}_{5}$ & 22.0 & $\mathrm{CO}_{4}$ \\
6 & 31.5 & $\mathrm{CO}_{4}$ & 21.2 & $\mathrm{CO}_{4}$ & 29.0 & $\mathrm{CO}_{4}$ \\
7 & 13.1 & $\mathrm{CO}_{5}$ & 9.3 & $\mathrm{CO}_{5}$ & 10.1 & $\mathrm{CO}_{5}$ \\
8 & 13.1 & $\mathrm{CO}_{5}$ & 16.8 & $\mathrm{CO}_{5}$ & 22.1 & $\mathrm{CO}_{4}$ \\
9 & 12.2 & $\mathrm{CO}_{5}$ & 9.0 & $\mathrm{CO}_{5}$ & 9.7 & $\mathrm{CO}_{5}$ \\
10 & 13.1 & $\mathrm{CO}_{5}$ & 10.7 & $\mathrm{CO}_{5}$ & 11.6 & $\mathrm{CO}_{5}$ \\
11 & 23.4 & $\mathrm{CO}_{4}$ & 15.8 & $\mathrm{CO}_{5}$ & 20.2 & $\mathrm{CO}_{5}$ \\
12 & 20.7 & $\mathrm{CO}_{5}$ & 14.4 & $\mathrm{CO}_{5}$ & 18.3 & $\mathrm{CO}_{5}$ \\
13 & 7.9 & $\mathrm{CO}_{5}$ & 11.0 & $\mathrm{CO}_{5}$ & 13.6 & $\mathrm{CO}_{5}$ \\
14 & 17.5 & $\mathrm{CO}_{5}$ & 12.6 & $\mathrm{CO}_{5}$ & 16.3 & $\mathrm{CO}_{5}$ \\
\hline
\end{tabular}

Legenda: Grau de semelhança: Nenhuma $=\mathrm{CO}_{5} ; \mathrm{Baixa}=\mathrm{CO}_{4} ;$ Média $=\mathrm{CO}_{3}$.

Ao se comparar o ano de 2011 com o de 2000 o quadro é bem mais positivo, pois se verifica que 5 sub-bacias apresentaram melhora no índice de semelhança da cobertura original (sub-bacias 1, 2, 5 e 8). Nenhuma sub-bacia apresentou piora e todas as demais sub-bacias mantiveram seus índices no período (Tabela 6).

Estes resultados estão de acordo com Campos (2013), sobre análise temporal da vegetação nativa em trechos da bacia do rio Ivaí, que verificou incremento substancial da vegetação protetora da rede hídrica entre os anos estudados (1970 e 2010). 


\section{Declividade média - Parâmetro DM}

A declividade da bacia é um parâmetro importante uma vez que está diretamente associada ao tempo de duração do escoamento superficial e de concentração da precipitação nos leitos dos cursos d'água. Isto afeta a forma e os valores máximos do hidrograma de escoamento na bacia. Associando os resultados da declividade expostos na Figura $4 \mathrm{com}$ as classes apresentadas na legenda, obteve-se a classificação da declividade média por sub-bacia, apresentados na Tabela 7.

Tabela 7 - Parâmetro DM por sub-bacia - bacia do rio Ivaí

\begin{tabular}{cccc}
\hline SUB-BACIA & DM & ÍNDICE & RELEVO \\
1 & 10,00 & $D M_{2}$ & Ondulado \\
2 & 10,00 & $D M_{2}$ & Ondulado \\
3 & 12,21 & $D M_{2}$ & Ondulado \\
4 & 12,20 & $D M_{2}$ & Ondulado \\
5 & 14,58 & $D M_{2}$ & Ondulado \\
6 & 12,66 & $D M_{2}$ & Ondulado \\
7 & 14,17 & $D M_{2}$ & Ondulado \\
8 & 12,56 & $D M_{2}$ & Ondulado \\
9 & 7,07 & $D M_{1}$ & Suave Ondulado \\
10 & 6,85 & $D M_{1}$ & Suave Ondulado \\
11 & 11,92 & $D M_{2}$ & Ondulado \\
12 & 10,65 & $D M_{2}$ & Ondulado \\
13 & 5,88 & $D M_{1}$ & Suave Ondulado \\
14 & 9,64 & $D M_{2}$ & Ondulado \\
\hline
\end{tabular}

De acordo com a Tabela 7, apenas 3 sub-bacias apresentaram relevo suave ondulado: sub-bacias 9, 10 e 13. As demais apresentaram relevo ondulado, com maiores percentuais médios de declive. De acordo com as informações numéricas, a sub-bacia que apresentou menor índice foi a 13 com 5,88 de declividade média e a de maior resultado foi a sub-bacia 5 , com valor de 14,58 . 


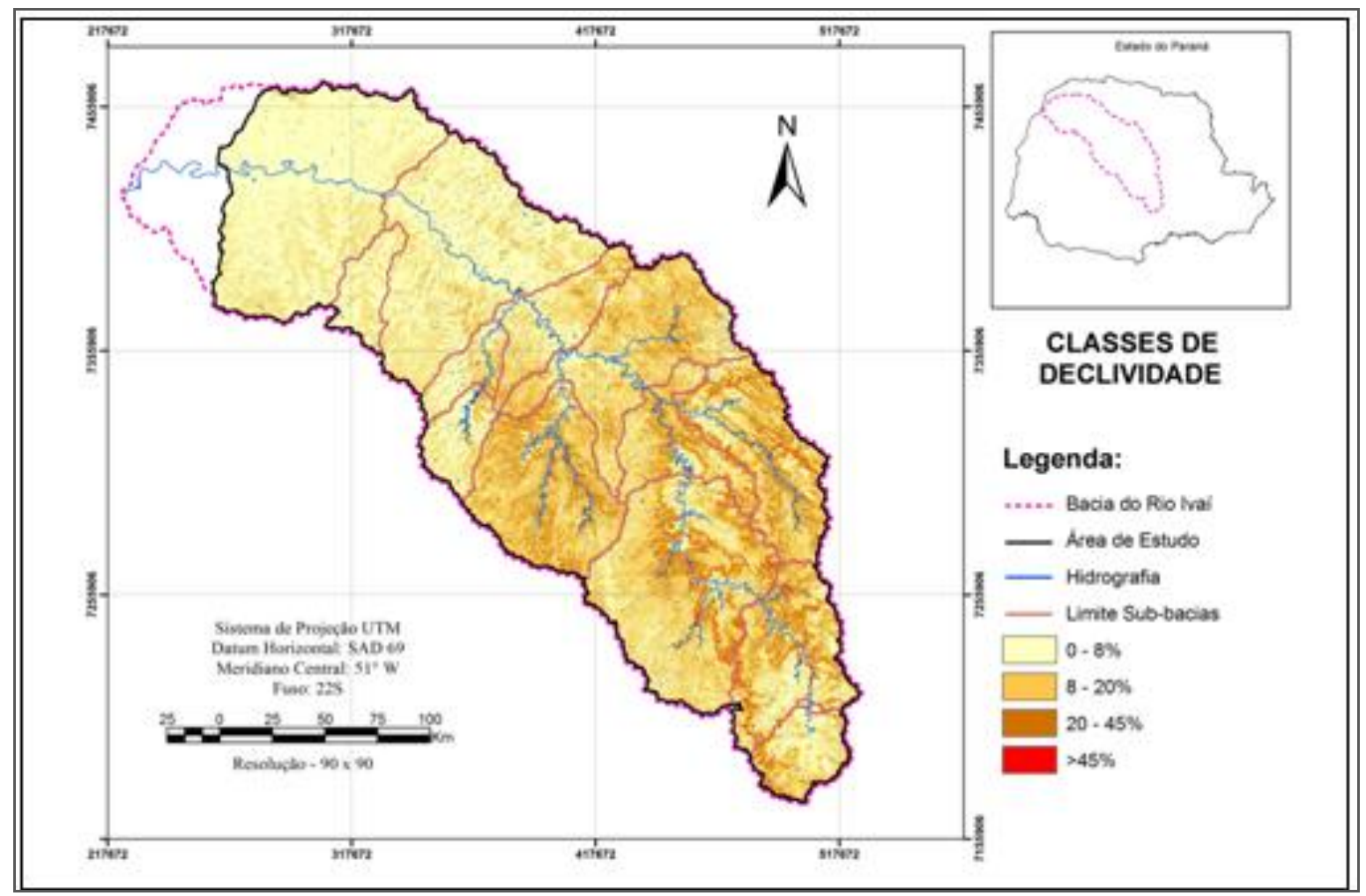

Figura 4 - Declividade da bacia do rio Ivaí - PR

\section{Erosividade da chuva - Parâmetro E}

Os resultados comparativos por sub-bacia estão dispostos na Tabela 8. Podese verificar que a sub-bacia $10(1776,3 \mathrm{~mm})$ apresentou maior média de ocorrência de chuvas, e a menor média pela sub-bacia 13 (1534,1 mm), assim com amplitude média de 242,2 $\mathrm{mm}$. Interessante notar que estas são as bacias amostrais que, dentre as 14 , são as que apresentam as menores áreas, $854,2 \mathrm{~km}^{2}$ e $802,5 \mathrm{~km}^{2}$, respectivamente.

De acordo com a Tabela 8, as sub-bacias 13 e 14 apresentaram erosividade débil, com índice abaixo de 670,15 t/ha.mm/h, e as demais apresentam erosividade média com índice acima de 670,15 e abaixo de 847,80 t/ha.mm/h. Estes resultados apontam que de forma geral para a bacia do rio Ivaí, a erosividade causada pela chuva não traz riscos significativos, mas sim moderados.

3.5 Potencial erosivo dos solos - Parâmetro PE

Esse parâmetro considera características a partir da vulnerabilidade do solo à erosão. O solo apresenta diversos aspectos que evidenciam a sua maior ou menor suscetibilidade à erosão em uma mesma área. Os resultados dos índices totais e 
seus respectivos símbolos do potencial erosivo dos solos para cada sub-bacia estão expostos na Tabela 9.

Tabela 8 - Parâmetro E por Sub-bacia - bacia do rio Ivaí - PR.

\begin{tabular}{cccc} 
Sub-bacia & Chuva $(\mathbf{m m})$ & $\begin{array}{c}\text { Indice } \\
(\mathbf{t} /(\mathbf{h a . m m} / \mathbf{h}))\end{array}$ & $\begin{array}{c}\text { Símbolo e } \\
\text { subíndice }\end{array}$ \\
1 & 1725,2 & 702,64 & $E_{2}$ \\
2 & 1725,7 & 695,03 & $E_{2}$ \\
3 & 1701,9 & 695,57 & $E_{2}$ \\
4 & 1720,8 & 702,55 & $E_{2}$ \\
5 & 1665,0 & 701,43 & $E_{2}$ \\
6 & 1701,1 & 697,90 & $E_{2}$ \\
7 & 1746,9 & 720,34 & $E_{2}$ \\
8 & 1691,8 & 695,31 & $E_{2}$ \\
9 & 1689,3 & 699,55 & $E_{2}$ \\
10 & 1776,3 & 721,80 & $E_{2}$ \\
11 & 1683,1 & 692,74 & $E_{2}$ \\
12 & 1650,8 & 683,39 & $E_{2}$ \\
13 & 1534,1 & 644,06 & $E_{1}$ \\
14 & 1613,2 & 667,36 & $E_{1}$ \\
\hline
\end{tabular}

Legenda: $E_{1}=$ erosividade débil; $E_{2}=$ erosividade média .

Tabela 9 - Potencial Erosivo dos Solos por sub-bacia e Respectivos Símbolos

\begin{tabular}{cccc}
\hline Sub-bacia & Potencial erosivo & Índice & Símbolo \\
\hline 1 & Alto a moderado & 0.0428 & $P E_{3}$ \\
2 & Alto a moderado & 0.0421 & $P E_{3}$ \\
3 & Alto a moderado & 0.0503 & $P E_{3}$ \\
4 & Alto a moderado & 0.0475 & $P E_{3}$ \\
5 & Alto a moderado & 0.0598 & $P E_{3}$ \\
6 & Alto a moderado & 0.0500 & $P E_{3}$ \\
7 & Alto a moderado & 0.0516 & $P E_{3}$ \\
8 & Alto a moderado & 0.0485 & $P E_{3}$ \\
9 & Moderado & 0.0265 & $P E_{2}$ \\
10 & Moderado & 0.0259 & $P E_{2}$ \\
11 & Alto a moderado & 0.0460 & $P E_{3}$ \\
12 & Alto a moderado & 0.0413 & $P E_{3}$ \\
13 & Moderado & 0.0287 & $P E_{2}$ \\
14 & Moderado & 0.0393 & $P E_{2}$ \\
\hline
\end{tabular}

Segundo Carvalho (2004), alguns autores afirmam que a erosão dos solos é um processo que ocorre em duas fases, sendo a primeira constituída pela remoção de partículas e a segunda referente ao transporte deste material. De um modo geral, as pesquisas sobre a erosão do solo consideram como fatores controladores dos processos erosivos a erosividade da chuva, as propriedades dos solos (como textura, densidade aparente, porosidade, teor de matéria orgânica, teor e 
estabilidade dos agregados e $\mathrm{pH}$ do solo), cobertura vegetal e características das encostas.

Abaixo se encontram a descrição das classes do potencial erosivo da bacia, em que estão incluídas informações dos resultados obtidos a partir da elaboração da matriz (Tabela 9) e também de considerações quanto à geomorfologia, geologia, hipsometria e recomendações de uso geral. As classes intermediárias foram agrupadas considerando-se uma variação para cima na coluna do potencial erosivo, com ênfase na declividade (Figura 5).

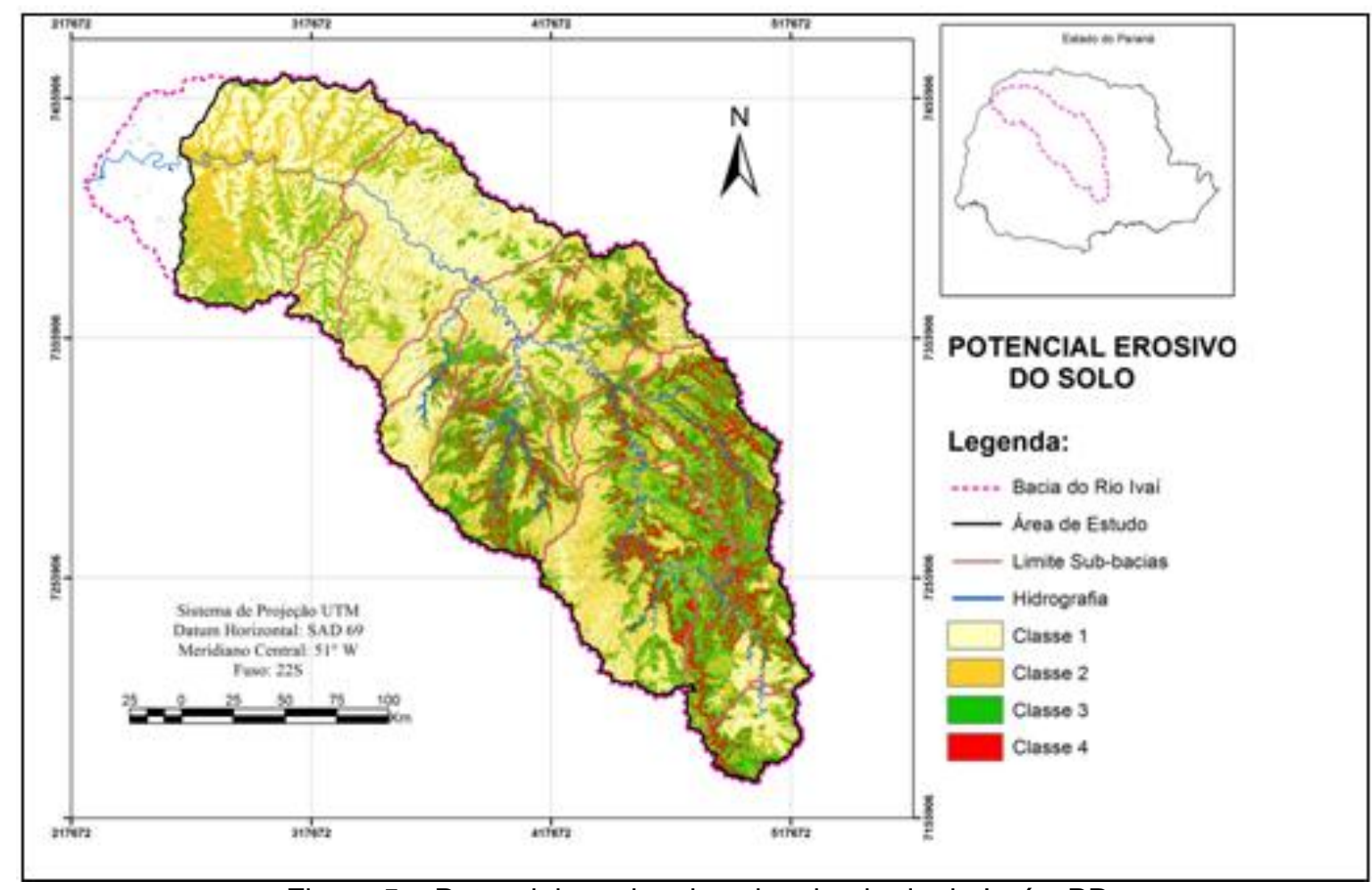

Figura 5 - Potencial erosivo do solo - bacia do rio Ivaí - PR

Classe 1 - Solos com baixo potencial erosivo: Latossolos (LBd; LVd; LVdf; LVe; LVef), Nitossolos (NBa; NBd; NVdf; NVef), Gleissolos (GM; GX) e Organossolos (OX) associados a áreas com relevo suave ondulado, declividade nunca superior a $8 \%$, estão presentes principalmente nas sub-bacias mais à montante (sub-bacias 1, 2 e 3), e da parte central até foz da bacia do Ivaí (subbacias 11, 12 e 13), onde as altitudes da bacia hidrográfica são menores. Estas áreas aparecem nos fundos de vales e se estendem seguindo o leito do rio principal por quase toda sua extensão e de alguns de seus afluentes de maior expressão. 
Esta classe corresponde a aproximadamente $11.000 \mathrm{~km}^{2}$, equivalendo a $32 \%$ da área total da bacia do rio Ivaí, ocorrendo em áreas da Formação Teresina, Formação Serra Geral e Formação Caiuá. Embora estes solos ocorram em áreas de baixa declividade, em algumas situações não são recomendáveis às culturas agrícolas, quando mal drenados e com a presença de várzeas e banhados (Gleissolos), impedindo o uso de equipamentos. Nas áreas onde ocorre o Latossolo as terras são adequadas à agricultura, com práticas simples no manejo (cultivo em curvas de nível, rotação de culturas, plantio direto, etc.).

Classe 2 - Solos com baixo a moderado potencial erosivo: Argissolos (PVAd; PVd; PVe); Cambissolos (CHa; CXbd); Latossolos (LVd; LVdf; LVef); Nitossolos (NBa; NVef), Gleissolos (GX); Neossolos (RRd; RRdh; RRe; RLdh; RYbd; RYq) e Organossolos (OX) associados a áreas com relevo ondulado, declividade variando entre 8 a 20\%. Ocorrem com maior frequência nas bases e nas meias encostas, mas apresentam pequenas áreas em topos de morros mais suaves. Corresponde a uma área de $12.855 \mathrm{~km}^{2}$, o que representa $37 \%$ da área total da bacia do rio Ivaí, presente em praticamente toda a bacia, por ser a classe de maior expressividade. Ocorrem praticamente em todas as ocorrências geológicas da área de estudo de modo uniforme. Os Latossolos são muito profundos, friáveis, muito porosos, acentuadamente drenados e de coloração variável. Os Nitossolos são profundos, argilosos, porosos, bem drenados, de coloração avermelhada. De modo geral, áreas com estas características, podem ser exploradas para culturas anuais, desde que sejam aplicadas práticas de manejo e de conservação do solo (plantio em nível, terraceamento, plantio direto, etc.), e respeitando os limites das áreas de preservação permanente.

Classe 3 - Solos com moderado a alto potencial erosivo: Argissolos (PVAd; PVd; PVe); Cambissolos (CHa; CXbd); Latossolos (LBd; LVd; LVdf; LVef); Nitossolos (NVef; NVdf); e Neossolos (RRe; RLdh) associados a áreas com relevo ondulado a forte ondulado, presentes nos topos mais declivosos e comumente no terço superior das encostas, com declividade bem diversificada, superior a $20 \%$. Em sua grande maioria estão sobrepostos ao embasamento geológico Formação Rio do Rasto. Esta classe ocupa $7.700 \mathrm{~km}^{2}$ ou $22 \%$ da área total da bacia, ocorre mais significativamente nas sub-bacias 3, 4 e 5 , onde as altitudes são maiores. Pelas suas características, são áreas não recomendadas ao uso agrícola devido à alta 
suscetibilidade à erosão, com fortes restrições ao uso de maneira geral, podendo ser utilizadas para reflorestamento com exploração seletiva no médio curso da bacia; no alto curso, entretanto, estas áreas devem ser destinadas à preservação ambiental permanente.

Classe 4 - Solos com alto a muito alto potencial erosivo: Argissolo (PVAd); Cambissolos (CHa; CXbd); Nitossolo (NBa); e Neossolos (RLdh; RRd; RRdh; RRe) associados a áreas com relevo montanhoso a escarpado, com declividade acima de $20 \%$ e nas encostas mais íngremes da bacia hidrográfica podendo superar a $45 \%$. Esta classe ocupa $2.858 \mathrm{~km}^{2}$ ou $9 \%$ da área total da bacia, ocorre mais significativamente nas sub-bacias $3,4,5,6$ e 7, especialmente na pequena área embasada pela Formação Piramboia e Botucatu. Abrange da parte central ao alto da bacia do rio Ivaí, com predominância dos solos frágeis, sem estrutura de suporte para utilização agrícola, devendo ser preservados, principalmente por estarem relacionados a altas declividades.

\subsection{Densidade de drenagem - Parâmetro DD}

A densidade de drenagem correlaciona o comprimento total dos canais de escoamento com a área da bacia hidrográfica. Tem relação inversa com os comprimentos dos rios, pois à medida que aumenta o valor numérico da densidade, há a diminuição quase proporcional do tamanho dos componentes fluviais da bacia.

A densidade de drenagem segundo Villela; Mattos (1975) é uma boa indicação do grau de desenvolvimento de um sistema de drenagem, pois varia inversamente com a extensão do escoamento superficial e, portanto, fornece uma indicação da eficiência da drenagem da bacia. Com base na classificação apresentada na Tabela 10, calculou-se a densidade de drenagem para cada subbacia, sua respectiva classificação e simbologia representativa.

De acordo com a Tabela 10, a sub-bacia 5 foi a que apresentou maior DD (Muito Alta), envolvendo as classes geológicas da Formação Teresina, onde se alternam argilitos, folhelhos e siltitos de cor cinza médio esverdeada, frequentes níveis de sílex e calcários esbranquiçados; Formação Serra Alta com lamitos e folhelhos cinza escuro a esverdeado; Formação Palermo com siltitos cinzentos, predominantemente bioturbados e laminações inclinadas e,; Formação Serra Geral com as soleiras de diabásio. 
Tabela 10 - Parâmetro DD por sub-bacia - bacia do rio Ivaí

\begin{tabular}{cccc}
\hline SUB-BACIA & $\mathbf{D D}\left(\mathbf{k m} / \mathbf{k m}^{\mathbf{2}}\right)$ & ÍNDICE & QUALIFICAÇÃO \\
1 & 2,50 & $D D_{3}$ & Alta \\
2 & 2,51 & $D D_{3}$ & Alta \\
3 & 3,32 & $D D_{3}$ & Alta \\
4 & 3,22 & $D D_{3}$ & Alta \\
5 & 4,23 & $D D_{4}$ & Muito alta \\
6 & 3,32 & $D D_{3}$ & Alta \\
7 & 1,86 & $D D_{2}$ & Mediana \\
8 & 2,83 & $D D_{3}$ & Alta \\
9 & 1,11 & $D D_{2}$ & Mediana \\
10 & 1,00 & $D D_{2}$ & Mediana \\
11 & 2,63 & $D D_{3}$ & Alta \\
12 & 2,28 & $D D_{3}$ & Alta \\
13 & 0,85 & $D D_{2}$ & Mediana \\
14 & 2,06 & $D D_{3}$ & Alta \\
\hline
\end{tabular}

As sub-bacias 1 a 4, 6, 11, 12 e 14 apresentaram DD Alta e as demais subbacias $(7,9,10$ e 13) apresentaram DD mediana, sendo que no geral (sub-bacia 14) a bacia do rio Ivaí apresenta DD alta (Tabela 10).

\section{Balanço hídrico - Parâmetro BH}

De acordo com Beltrame (1994), o balanço hídrico é muito importante nesta análise, pois é considerado como mais um indicador do potencial natural de degradação ou conservação física da bacia. Se houver desequilíbrios na relação de entrada e saída da água, podem ocorrer danos irreversíveis aos recursos naturais.

Outro parâmetro importante derivado do balanço hídrico é o déficit hídrico, que corresponde à correlação entre a precipitação e a evapotranspiração, indicando a duração e a época da estação seca (Beltrame, 1994). No período de 1985 a 2012 verificou-se que nas estações que compreende a bacia do rio Ivaí houve apenas excedente hídrico (Figura 6).

O total anual geral foi igual a $619,39 \mathrm{~mm}$ (Tabela 11), qualificado como índice médio (representado pela sub-bacia 14). As sub-bacias 1 e 2 foram as que apresentaram maiores índices de $\mathrm{BH}$, com excedentes de 873,59 mm e 839,59 mm, respectivamente, considerados como $\mathrm{BH}$ alto, de acordo com a metodologia. 


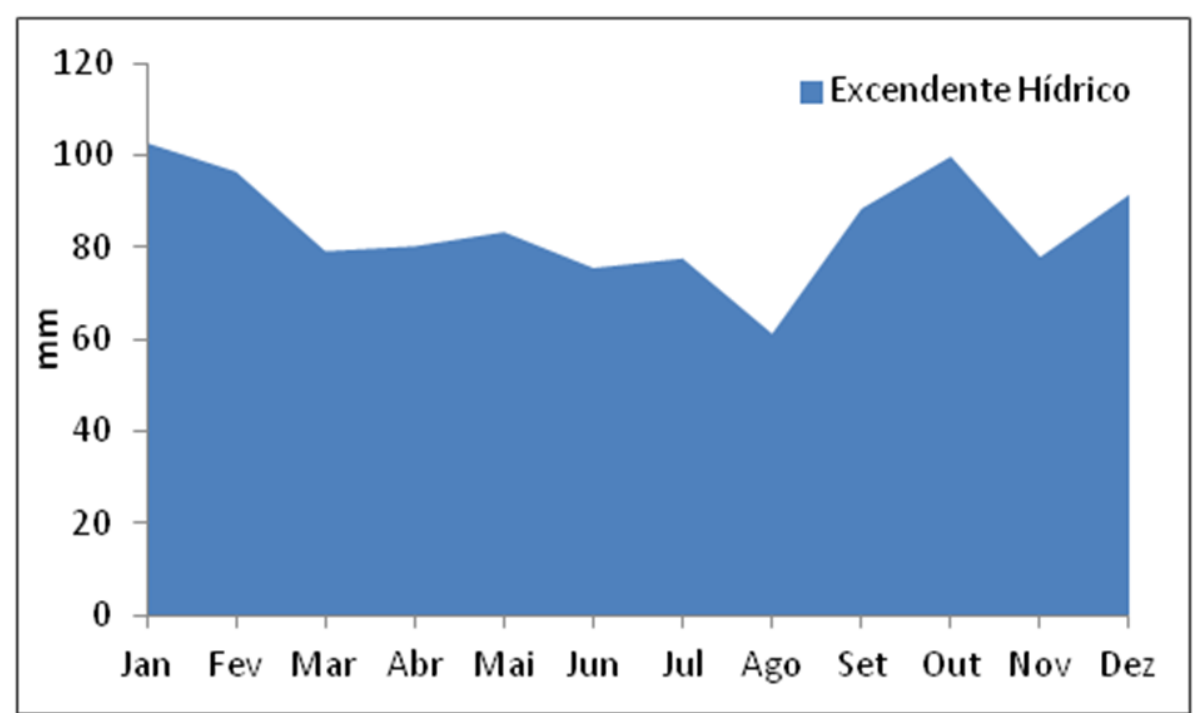

Figura 6 - Extrato do Balanço Hídrico para a Bacia do rio Ivaí, 1985 - 2012.

Tabela 11 - Parâmetro BH por sub-bacia - bacia do rio Ivaí.

\begin{tabular}{ccccc} 
Tabela 11 - Parâmetro BH por sub-bacia - bacia do rio lvaí. & & \\
\hline $\begin{array}{c}\text { SUB- } \\
\text { BACIA }\end{array}$ & $\begin{array}{c}\text { Chuva } \\
(\mathbf{m m})\end{array}$ & $\begin{array}{c}\text { Evapotrans- } \\
\text { piração } \\
\text { (mm) }\end{array}$ & $\begin{array}{c}\text { EXCEDENTE } \\
\text { (mm) }\end{array}$ & ÍNDICE \\
1 & 1725,2 & 852 & 873,59 & $\mathrm{BH}_{2}$ \\
2 & 1725,7 & 887 & 839,05 & $\mathrm{BH}_{2}$ \\
3 & 1701,9 & 974 & 727,61 & $\mathrm{BH}_{3}$ \\
4 & 1720,8 & 950 & 770,59 & $\mathrm{BH}_{3}$ \\
5 & 1665,0 & 1007 & 657,67 & $\mathrm{BH}_{3}$ \\
6 & 1701,1 & 990 & 710,96 & $\mathrm{BH}_{3}$ \\
7 & 1746,9 & 1008 & 738,62 & $\mathrm{BH}_{3}$ \\
8 & 1691,8 & 953 & 738,69 & $\mathrm{BH}_{3}$ \\
9 & 1689,3 & 994 & 695,10 & $\mathrm{BH}_{3}$ \\
10 & 1776,3 & 1048 & 728,43 & $\mathrm{BH}_{3}$ \\
11 & 1683,1 & 970 & 713,36 & $\mathrm{BH}_{3}$ \\
12 & 1650,8 & 1014 & 636,51 & $\mathrm{BH}_{3}$ \\
13 & 1534,1 & 986 & 547,80 & $\mathrm{BH}_{3}$ \\
14 & 1613,2 & 994 & 619,39 & $\mathrm{BH}_{3}$ \\
\hline
\end{tabular}

Legenda: $\mathrm{BH}_{2}=$ excedente hídrico alto; $\mathrm{BH}_{3}=$ excedente hídrico médio.

As demais sub-bacias apresentaram médios índices de $\mathrm{BH}$, com excedentes variando entre $547,80 \mathrm{~mm}$ (sub-bacia 13) e 770,59 mm (sub-bacia 4). 


\section{Cálculo do valor do processo de degradação}

Os resultados da síntese dos parâmetros dos fatores potenciais de degradação dos recursos naturais, do DFC estão expressos de forma numérica e na forma dos percentuais resultantes do uso da equação 2, na Tabela 12.

Tabela 12 - Potencial de degradação por sub-bacia - bacia do rio Ivaí.

\begin{tabular}{c|ccc|c|c|c|c|c}
\hline \multirow{2}{*}{ Sub-bacia } & \multicolumn{2}{|c|}{ Ano 1986 } & \multicolumn{2}{c|}{ Ano 2000 } & \multicolumn{2}{c|}{ Ano 2011 } & \multirow{2}{*}{ DFC médio (\%) } \\
\cline { 2 - 6 } & DFC & $\begin{array}{c}(0- \\
\text { (00\%) }\end{array}$ & DFC & $\begin{array}{c}(0- \\
100 \%)\end{array}$ & DFC & $\begin{array}{c}(0- \\
100 \%)\end{array}$ & \\
\hline 1 & 17 & 41,72 & 18 & 45,89 & 17 & 41,72 & 43,11 \\
2 & 17 & 41,72 & 18 & 45,89 & 17 & 41,72 & 43,11 \\
3 & 18 & 45,89 & 19 & 50,06 & 19 & 50,06 & 48,67 \\
4 & 19 & 50,06 & 19 & 50,06 & 19 & 50,06 & 50,06 \\
5 & 20 & 54,23 & 22 & 62,57 & 20 & 54,23 & 57,01 \\
6 & 19 & 50,06 & 19 & 50,06 & 19 & 50,06 & 50,06 \\
7 & 19 & 50,06 & 20 & 54,23 & 20 & 54,23 & 52,84 \\
8 & 20 & 54,23 & 21 & 58,40 & 19 & 50,06 & 54,23 \\
9 & 18 & 45,89 & 18 & 45,89 & 18 & 45,89 & 45,89 \\
10 & 18 & 45,89 & 18 & 45,89 & 18 & 45,89 & 45,89 \\
11 & 19 & 50,06 & 21 & 58,40 & 20 & 54,23 & 54,23 \\
12 & 20 & 54,23 & 21 & 58,40 & 21 & 58,40 & 57,01 \\
13 & 17 & 41,72 & 16 & 37,55 & 17 & 41,72 & 40,33 \\
14 & 18 & 45,89 & 19 & 50,06 & 19 & 50,06 & 48,67 \\
\hline
\end{tabular}

Como podem ser visualizadas através da Tabela 12 e Figura 7, as sub-bacias 4, 6, 9 e 10 não apresentaram variações nos resultados para o DFC entre os anos analisados (1986, 2000 e 2011).

As sub-bacias que apresentaram os menores percentuais de degradação foram: 13, 1 e 2 e as sub-bacias de maior DFC ou potencial de degradação foram: 5 (destaque principalmente para o ano de 2000), 8, 11 (destaque para o ano de 2000) e 12 (destaque para os anos de 2000 e 2011). De forma geral, a bacia do rio Ivaí, representada pela sub-bacia 14 , apresenta potencial de degradação mediano, com percentual de 50,06\% em 2000, com queda no percentual em relação ao ano de 1986. Estes dados foram utilizados na validação do método. 


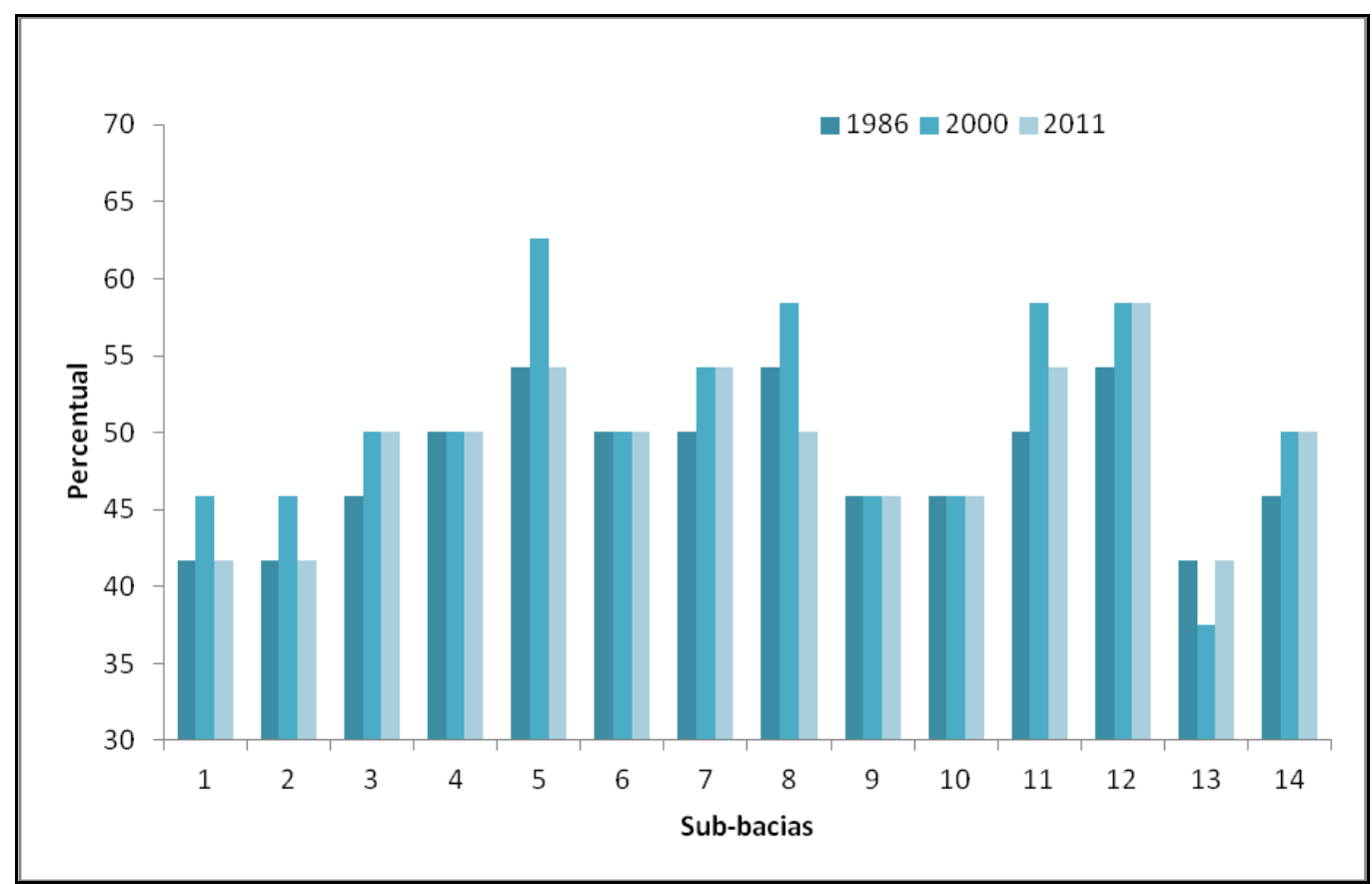

Figura 7 - Dados comparativos do DFC por sub-bacia (1986, 2000 e 2011).

\section{Análise de Correlação Canônica (ACC)}

A Tabela 13 apresenta os dados que compõem o primeiro grupo canônico de variáveis que, ao serem relacionados pelo método estatístico multivariado, confirmam o método de análise fisiográfica em bacias hidrográficas (segundo grupo de variáveis - DFC). Assim, o grupo das variáveis independentes são 09: vazão média $-Q(T P)$; vazão máxima $-Q$ (máx), as vazões mínimas (de 7, 15, 30, 60 e 90 dias), o desvio padrão (DESVPAD) e o coeficiente de variação $(C V)$, do período médio de 1985 a 2012.

Tabela 13. Principais parâmetros hidrológicos por sub-bacia - rio Ivaí PR.

\begin{tabular}{cccccccccc}
\hline Sub-bacia & !(TP) & DP & CV & $Q($ máx $)$ & $Q($ mín7) & $Q($ mín15) & $Q($ mín30) & $Q($ mín60) & $Q($ mín90) \\
\hline 1 & 27.7 & 26.88 & 0.92 & 291.7 & 3.6 & 4.1 & 5.0 & 6.7 & 9.3 \\
2 & 26.6 & 24.89 & 0.86 & 286.5 & 3.7 & 4.2 & 5.1 & 6.6 & 9.3 \\
3 & 23.1 & 21.70 & 0.26 & 332.0 & 2.9 & 3.3 & 4.1 & 5.5 & 9.1 \\
4 & 24.4 & 20.39 & 0.10 & 245.3 & 3.9 & 4.6 & 5.4 & 6.8 & 9.0 \\
5 & 20.9 & 18.83 & 0.35 & 335.8 & 2.4 & 2.7 & 3.3 & 4.5 & 6.7 \\
6 & 22.5 & 18.62 & 0.07 & 244.9 & 3.9 & 4.4 & 5.1 & 6.4 & 8.5 \\
7 & 23.4 & 22.46 & 0.29 & 447.4 & 1.8 & 2.1 & 2.7 & 3.9 & 6.4 \\
8 & 23.4 & 19.93 & 0.04 & 272.0 & 3.7 & 4.1 & 4.8 & 6.3 & 8.4 \\
9 & 22.0 & 9.70 & 0.28 & 149.1 & 8.7 & 9.8 & 10.9 & 12.3 & 13.3
\end{tabular}


Continuação...

\begin{tabular}{cccccccccc}
\hline Sub-bacia & !(TP) & DP & CV & Q(máx) & Q(mín7) & Q(mín15) & Q(mín30) & Q(mín60) & Q(mín90) \\
\hline 10 & 23.1 & 10.06 & 0.51 & 89.0 & 8.2 & 9.6 & 11.2 & 13.2 & 14.6 \\
11 & 22.6 & 16.82 & 0.03 & 206.8 & 5.1 & 5.5 & 6.2 & 7.6 & 9.6 \\
12 & 20.2 & 14.13 & 0.02 & 152.6 & 5.6 & 6.0 & 6.6 & 7.8 & 9.5 \\
13 & 17.4 & 5.41 & 0.39 & 76.3 & 10.8 & 11.3 & 11.8 & 12.7 & 13.3 \\
14 & 19.6 & 12.53 & 0.02 & 107.5 & 6.7 & 7.0 & 7.6 & 8.7 & 10.1 \\
\hline
\end{tabular}

Legenda: $\mathrm{Q}=$ Vazão; TP = Tempo de Permanência; DP = Desvio Padrão; CV = Coeficiente de Variação; $Q($ máx $)=$ Vazões Máximas Anuais (valores médios); Q(mín) = Vazões mínimas (valores médios).

\section{Correlação Canônica aplicada ao DFC}

Os resultados da correlação canônica aplicada ao DFC podem ser visualizados na Tabela 14, a seguir.

Tabela 14. Correlações canônicas: DFC versus vazão - bacia do rio Ivaí.

\begin{tabular}{ccccc}
\hline R canônico & $\begin{array}{c}\mathrm{R}^{2} \\
\text { canônico }\end{array}$ & Qui-quadrado & $\mathrm{GL}$ & $\mathrm{p}$-valor \\
\hline 0.978 & 0.957 & 26.681 & 9 & $<0.002$ \\
\hline
\end{tabular}

\begin{tabular}{lllllllll}
$Q$ (média) & $D E S V P A D$ & $C V$ & $Q($ máx $)$ & $Q($ mín7) & $Q($ mín15) & $Q($ mín30) & $Q($ mín60) & $Q($ mín90) \\
\hline
\end{tabular}

$\begin{array}{lllllllll}-0.172 & 0.166 & 0.378 & 0.342 & -0.515 & -0.527 & -0.542 & -0.552 & -0.616\end{array}$

Legenda: $Q=$ Vazão $\left(\mathrm{l} / \mathrm{s} / \mathrm{km}^{2}\right) ; D E S V P A D=$ Desvio Padrão $\left(1 / \mathrm{s} / \mathrm{km}^{2}\right) ; C V=$ Coeficiente de Variação $\left(1 / \mathrm{s} / \mathrm{km}^{2}\right) ; Q(m a ́ x)=$ Vazões Máximas Anuais (valores médios) $\left(1 / \mathrm{s} / \mathrm{km}^{2}\right) ; Q($ mín $)=$ Vazões Mínimas Diárias (valores médios) (1/s/km²).

Para o DFC o resultado da correlação canônica, representada pelo $R$ canônico foi igual a 0.978 com $R$ canônico elevado ao quadrado de 0.957 , quiquadrado $\left(x^{2}\right)$ de 26.681 e GL (graus de liberdade) igual a 9 com $p$-valor $<0,002$, o que é muito significativo e expressa alta correlação entre o método e as vazões, principalmente no que se refere as vazões mínimas de 30,60 e 90 dias. Estes resultados confirmam a hipótese de que o DFC pode ser validado pela vazão, pois de acordo com os resultados, eles não são independentes e estão altamente relacionados e sua eficiência pode assim ser confirmada (AYRES et al., 2007; BOGO et al., 2010).

Helfer et al. (2006) ao apresentarem um novo método na área alimentícia para a análise qualitativa de essências, também validaram o método com o emprego da estatística multivariada. Como os dados de vazão representam os processos dos 
elementos da paisagem, a validação pela alta correlação entre os elementos hidrológicos em confronto com os elementos físicos que o método do DFC propõe estão coerentes entre si. Isto é significativo tendo em vista que o método do DFC não contempla elementos hidrológicos de vazão no levantamento do meio físico que apresenta bem como o fato de propor pesos numéricos na caracterização em alguns parâmetros, o que aparentemente fragilizava o método.

Além disso, os diversos aspectos de vazão propostos para a validação são muito importantes na hidrologia. Por exemplo, para o planejamento ambiental as medições extremas (vazões mínimas e máximas) são no geral mais relevantes do que as vazões médias, pois são as informações mais utilizadas na verificação das cheias e dos períodos de estiagem para a tomada de decisões. Neste caso o DFC mostrou-se uma excelente ferramenta de levantamento do meio físico, principalmente para a regionalização das vazões mínimas (Tabela 14).

\section{CONCLUSÃO}

A análise de correlação canônica aplicada permite associar os diversos tipos de vazão, com o método do DFC, podendo assim verificar a eficiência do método. Os resultados da análise efetuada permitiram concluir que: 1. As correlações canônicas foram elevadas considerando um nível de significância igual a 5\%; 2. As análises de correlação canônica permitem observar que os grupos considerados não são independentes, isto é os grupos considerados estão fortemente correlacionados; 3. Estes resultados demonstram que o método do DFC reflete a realidade dos elementos físicos da paisagem e seus processos e que a atribuição de pesos numéricos para se chegar a generalizações sobre áreas estudadas são coerentes com a realidade.

\section{Referências bibliográficas}

ÁGUASPARANÁ - Superintendência de Desenvolvimento de Recursos Hídricos e Saneamento Ambiental. Base hidrográfica do Estado do Paraná (meio digital). Curitiba: 2011.

ALVARENGA, M. I. N.; PAULA, M. B. Planejamento conservacionista em microbacia. Informe agropecuário. Belo Horizonte, v. 21, n. 207, p. 55-64, 2000. 
AYRES, M., AYRES JR., M., AYRES, D. L., SANTOS, A. S. BioEstat. Versão 5.3, Sociedade Civil Mamirauá, MCT - CNPq, Belém, Pará, Brasil. 2007.

BALDO, M. C. Variabilidade pluviométrica e a dinâmica atmosférica na bacia hidrográfica do rio Ivaí - PR. Presidente Prudente, 2006. 172p. Tese (Doutorado em Geografia), Universidade Estadual Paulista.

BELTRAME, A. V. Diagnóstico do meio físico de bacias hidrográficas: modelo e aplicação. Florianópolis: Ed. da UFSC, 1994.

BOGO, R. L.; GRAMANI, L. M.; NETO, A. C.; BALBO, F. A. N. Análise de correlação canônica aplicada ao fluxo de tráfego veicular - estudo de caso da rodovia federal BR-116. Asociación Argentina de Mecánica Computacional. Vol. XXIX, p. 20712081. Buenos Aires, Argentina, 2010.

CAMPOS, R. M. Análise quantitativa e temporal da área mata ciliar de trechos da bacia do rio Ivaí - Paraná - Brasil. Maringá, 2013, 37 p. Dissertação (Mestrado em Agronomia) Universidade Estadual de Maringá.

CANTO, M.W.; JOBIM, C. C.; PAGLIARINI, M. S.; PANCERA JÚNIOR, E.; BARTH, NETO, A.; INTROVINI, E. P.; ZANFOLIN, P. R. L.; FERREIRA, C. W.; MATIVI, T. M.; ALMEIDA, G. M.; VIZZOTTO, B. A pecuária de corte no Paraná - desenvolvimento, caracterização e o papel das pastagens. Scientia Agraria Paranaensis (Cascavel) 9. 3 (2010): 05-21.

CARAMORI, P. H. Caracterização Climática. In: Instituto Agronômico do Paraná. Potencial de Uso agrícola das áreas de várzea do Estado do Paraná: bacia hidrográfica do baixo Ivaí. Boletim Técnico. Londrina, n.24, v.1, p.65-69, 1989.

CARVALHO, S. M. O diagnóstico físico-conservacionista - DFC como subsídio à gestão ambiental da bacia hidrográfica do rio Quebra-Perna, Ponta Grossa PR. Presidente Prudente, 2004. 183p. Tese (Doutorado em Geografia), Universidade Estadual Paulista.

COSTA, G. Análise de correlação canônica entre conjuntos de princípios da qualidade total. Cadernos de Administração, 1, 2008.

EBISEMIJU, F.S. Canonical correlation analysis in geomorphology with particular reference to drainage basin characteristics. Amsterdam, Geomorphology, 1, p. 331342. 1988.

EMBRAPA. Centro Nacional de Pesquisa de Solos. Sistema brasileiro de classificação de solos. Rio de Janeiro: Embrapa Solos, 2008.

EMBRAPA. Empresa Brasileira de Pesquisa Agropecuária. Serviço nacional de levantamento e conservação de solos. Levantamento de reconhecimento dos solos do estado do Paraná. Londrina: IAPAR. Dois tomos, 1984.

FERRETTI, E. R. Diagnóstico Físico-Conservacionista - DFC: Instrumento para o 
Plano de Bacias Hidrográficas - uma aplicação na Bacia do Rio Tagaçaba Município de Guaraqueçaba - PR. 2003. Tese (Doutorado em Geologia) Universidade Federal do Paraná, Curitiba, 2003.

FORNELOS, L. F.; SILVA NEVES, S. M. A. Uso de modelos digitais de elevação (MDE) gerados a partir de imagens de radar interferométrico (SRTM) na estivativa de perdas de solo. Anais... 1ํ Simpósio de Geotecnologias no Pantanal, Campo Grande, Brasil, 11-15 de novembro de 2006, Embrapa Informática Agropecuária/INPE, p. 182-191.

HELFER, G.; FERRÃO, M.; FERREIRA, C.; HERMES, N. Aplicação de métodos de análise multivariada no controle qualitativo de essências alimentícias empregando espectroscopia no infravermelho médio. Ciênc. Tecnol. Aliment., Campinas, 26(4): 779-786, out.-dez. 2006.

IAPAR - INSTITUTO AGRONÔMICO DO ESTADO DO PARANÁ. Cartas climáticas do Estado do Paraná. Londrina, IAPAR, 1994. 49 p. ( Documento, 18).

IBAMA - INSTITUTO BRASILEIRO DO MEIO AMBIENTE E DOS RECURSOS NATURAIS RENOVÁVEIS-IBAMA. Proteção e Recuperação da Floresta com Araucárias. Brasília: Ed. IBAMA. 2005.

IBGE - INSTITUTO BRASILEIRO DE GEOGRAFIA E ESTATÍSTICA. Manual Técnico de Uso da Terra. Rio de Janeiro, 2013.

IBGE - INSTITUTO BRASILEIRO DE GEOGRAFIA E ESTATÍSTICA. Levantamento sistemático da produção agropecuária. Rio de Janeiro, 2011.

IPARDES - INSTITUTO PARANAENSE DE DESENVOLVIMENTO ECONÔMICO E SOCIAL. Indicadores ambientais por bacias hidrográficas do Estado do Paraná. Curitiba, Ipardes, 2007. 98p.

INPE - INSTITUTO NACIONAL DE PESQUISAS ESPACIAIS. Imagens de satélite LANDSAT TM 5, anos 1986, 2000 e 2011. Disponíveis em http://dgi.inpe.br/CDSR/. Acesso em 08 de abril de 2013.

LEPSCH, I. F. Formação e conservação dos solos. São Paulo: Oficinas de Textos, 2002, $178 \mathrm{p}$.

MAACK, R. Geografia Física do Estado do Paraná. $2^{\circ}$ edição. Rio de Janeiro: Livraria José Olympio Editora, 1981.

MENDONÇA, F.; MARQUES, G. S. Degradação ambiental e qualidade da água em bacia hidrográfica de abastecimento público: rio Timbú - PR. Entre-Lugar. Dourados, MS, ano 2, n. 3, p. 111-136, 2011.

MINEROPAR. Atlas geológico do estado do Paraná. Curitiba: 2006. Escala $1: 250.000$. 
NEVES, E. H. Análise da degradação ambiental da bacia hidrográfica do Arroio Pelotas-RS, através do diagnóstico físico conservacionista (DFC). Porto Alegre, 2012. 158p. Dissertação (Mestrado em Geografia), Universidade Federal do Rio Grande do Sul.

OKA-FIORI C.; SANTOS L. J. C.; CANALI N. E.; FIORI A. P.; SILVEIRA C. T.; SILVA J. M. F.; ROSS J. L. S. Atlas Geomorfológico do Estado do Paraná: escala base 1:250.000, modelos reduzidos 1:500.000. Curitiba, MINEROPAR, 59p. 2006.

PARANÁ. Decreto Estadual o 387 de 02 de março de 1999 (Institui o Sistema de Manutenção, Recuperação e Proteção da Reserva Florestal Legal e Áreas de Preservação Permanente - SISLEG, no Estado do Paraná).

RAMALHO FILHO, A.; BEEK, K. J. Sistema de avaliação da aptidão agrícola das terras. $3^{\underline{a}}$ ed. Rio de Janeiro: EMBRAPA-CNPS, 1994. 65p.

ROSS, J. L. S. Análise empírica da fragilidade dos ambientes naturais e antropizados. Revista do departamento de geografia, ํㅡㅇ․ USP, 1994.

TORRANIN, P. Applicability of canonical correlation in hydrology. Colorado State University, Hydrology Paper. No. 58. 1972.

TRUGILHO, P. F.; LIMA, J. T.; MORI, F. A. Correlação canônica das características químicas e físicas da madeira de clones de eucalyptus grandis e eucalyptus saligna. CERNE, n. 9, p. 66-80, 2003.

VELOSO, H. P.; RANGEL FILHO, A. L.R; LIMA, J. C. A. Classificação da vegetação brasileira, adaptada a um sistema universal. Rio de Janeiro: IBGE, 1991. 123p.

VILLELA, S. M.; MATTOS, A. Hidrologia Aplicada. São Paulo: McGraw-Hill do Brasil, 1975, p. 8 - 28.

(Recebido em 02.06.2014; Aceito em: 20.02.2015) 